\title{
Geomorphic Constraints on Listric Thrust Faulting: Implications for Active Deformation in the Mackenzie Basin, South Island, New Zealand
}

Colin Amos

Western Washington University, colin.amos@wwu.edu

Douglas W. Burbank

David C. Nobes

Stuart A. L. Read

Follow this and additional works at: https://cedar.wwu.edu/geology_facpubs

Part of the Geology Commons, Geomorphology Commons, and the Geophysics and Seismology Commons

\section{Recommended Citation}

Amos, Colin; Burbank, Douglas W.; Nobes, David C.; and Read, Stuart A. L., "Geomorphic Constraints on Listric Thrust Faulting: Implications for Active Deformation in the Mackenzie Basin, South Island, New Zealand" (2007). Geology Faculty Publications. 98.

https://cedar.wwu.edu/geology_facpubs/98

This Article is brought to you for free and open access by the Geology at Western CEDAR. It has been accepted for inclusion in Geology Faculty Publications by an authorized administrator of Western CEDAR. For more information, please contact westerncedar@wwu.edu. 


\title{
Geomorphic constraints on listric thrust faulting: Implications for active deformation in the Mackenzie Basin, South Island, New Zealand
}

\author{
Colin B. Amos, ${ }^{1}$ Douglas W. Burbank, ${ }^{1,2}$ David C. Nobes, ${ }^{3}$ and Stuart A. L. $\operatorname{Read}^{4}$
}

Received 16 January 2006; revised 17 June 2006; accepted 4 August 2006; published 9 February 2007.

[1] Deformed fluvial terraces preserved over active thrust-related folds record the kinematics of folding as fault slip accumulates on the underlying thrust. In the Mackenzie Basin of southern New Zealand, the kinematics revealed by folded fluvial terraces along the active Ostler and Irishman Creek fault zones are inconsistent with traditional models for thrust-related folding in which spatially uniform rock uplift typically occurs over planar fault ramps. Instead, warped and tilted terraces in the Mackenzie are characterized by broad, continuous backlimbs and abrupt forelimbs and suggest folding through progressive limb rotation. By relating this pattern of surface deformation to the underlying thrust with a newly developed, simple geometric and kinematic model, we interpret both faults as listric thrusts rooted at depth into gently dipping planar fault ramps. Constraints on the model from detailed topographic surveying of deformed terraces, ground-penetrating radar over active fault scarps, and luminescence dating of terrace surfaces suggest slip rates for the Ostler and Irishman Creek faults of $\sim 1.1-$ $1.7 \mathrm{~mm} / \mathrm{yr}$ and $\sim 0.5-0.7 \mathrm{~mm} / \mathrm{yr}$, respectively. The predicted depth of listric faulting for the Ostler fault $\left(0.7_{-0.2}^{+0.1} \mathrm{~km}\right)$ and the Irishman Creek fault $\left(1.3_{-0.5}^{+0.1} \mathrm{~km}\right)$ generally agrees with geophysical estimates of basin depth in the Mackenzie and suggests control of preexisting basin architecture on the geometry of active thrusting. Despite the potential effects of changes in fault curvature and hanging wall internal deformation, the methodology presented here provides a simple tool for approximating the kinematics of surface deformation associated with slip along listric, or curviplanar, thrust faults.

Citation: Amos, C. B., D. W. Burbank, D. C. Nobes, and S. A. L. Read (2007), Geomorphic constraints on listric thrust faulting: Implications for active deformation in the Mackenzie Basin, South Island, New Zealand, J. Geophys. Res., 112, B03S11, doi:10.1029/2006JB004291.

\section{Introduction}

[2] Thrust fault systems represent a fundamental and ubiquitous manifestation of deformation in active collisional orogens. Such systems exert primary control on the structure and development of active contractional mountain belts by localizing compressional strain in response to crustal shortening. Because the sequential kinematic development of ancient thrust systems is commonly difficult to reconstruct [e.g., Boyer and Elliot, 1982], progressively deformed geomorphic features, such as river terraces, provide indispensable records of both finite and incremental strain incurred through active thrusting. Increasing attention

\footnotetext{
${ }^{1}$ Department of Earth Science, University of California, Santa Barbara, California, USA.

${ }^{2}$ Institute for Crustal Studies, University of California, Santa Barbara, California, USA.

${ }^{3}$ Department of Geological Sciences, University of Canterbury, Christchurch, New Zealand.

${ }^{4}$ Institute of Geological and Nuclear Sciences Ltd., Lower Hutt, New Zealand.

Copyright 2007 by the American Geophysical Union. 0148-0227/07/2006JB004291\$09.00
}

focused on linking surface folding of fluvial terraces with thrusting at depth both for individual coseismic events [e.g., King and Vita-Finzi, 1981; Philip and Meghraoui, 1983; Stein and King, 1984; Nicol and Campbell, 2001] and integrated over multiple earthquake cycles [Rockwell et al., 1984, 1988; Bullard and Lettis, 1993; Molnar et al., 1994; Benedetti et al., 2000; Keller et al., 2000; Lavé and Avouac, 2000; Thompson et al., 2002; Campbell et al., 2003; Formento-Trigilio et al., 2003; Ishiyama et al., 2004; Gold et al., 2006; Scharer et al., 2006] highlights the potential for deformed geomorphic markers to elucidate the kinematic history of thrust related folds at Quaternary timescales.

[3] Through integration of bedrock structural measurements with neotectonic observations at the surface, several workers have successfully utilized models for fold and thrust evolution such as fault bend folding [Molnar et al., 1994; Lavé and Avouac, 2000; Thompson et al., 2002; Ishiyama et al., 2004], fault propagation folding [Bullard and Lettis, 1993; Benedetti et al., 2000] and trishear fault propagation folding [Gold et al., 2006] in characterizing suites of deformed terraces. Because each of these models predicts contrasting patterns of differential uplift, their 
application to describing terrace deformation requires matching kinematic predictions of deformed surfaces with specific fault and fold geometries and progressive slip at depth. For the case of fault bend folding [Suppe, 1983] and fault propagation folding [Suppe and Medwedeff, 1990], folding is largely concentrated in distinct kink bands developed over angular bends in otherwise planar faults. With the exception of folding above trishear zones formed above propagating fault tips [Erslev, 1991] or kinks in planar faults ramps [Cristallini and Allmendinger, 2002], differential uplift associated with such models is broadly uniform within each dip domain defined by planar fault segments at depth [Hardy and Poblet, 2005].

[4] Here, we focus on the geomorphic expression of folding associated with listric thrust faults or curviplanar thrusts that increase in dip toward the surface. Although previously described for inactive thrust systems [Erslev, 1986; Erslev and Rogers, 1993], range-scale thrusts [Seeber and Sorlien, 2000; Abdrakhmatov et al., 2001; Pinter et al., 2001], and offshore thrust complexes [Barnes et al., 2002], the geometry and kinematics of surface folding associated with active, listric thrust faults remains relatively unexplored. In contrast to folds developed over planar fault ramps, folding over listric thrusts produces spatially nonuniform rock uplift rates [Pinter et al., 2001] and results in progressive limb rotation as fault slip accumulates. By developing simple, combined geometric and kinematic models for terrace deformation over listric thrusts, we demonstrate how such models can (1) be used to predict differential uplift patterns and differentiate between contrasting types of thrust-related folding, (2) provide consistent estimates of fault slip rates in the presence of age control on deformed terrace surfaces, and (3) allow reasonable constraints on the geometry of faulting at depth in the absence of detailed seismic control.

[5] We then apply this simple model using a combination of detailed geomorphic mapping and surface age dating, ground-penetrating radar, and high-resolution topographic surveying of warped and tilted terrace surfaces along two Quaternary thrusts, the Ostler and Irishman Creek fault zones in the Mackenzie Basin of southern New Zealand (Figure 1). There, nested suites of remarkably wellpreserved fluvial terraces and outwash surfaces display fold geometries consistent with listric thrust faulting at depth. By demonstrating the compatibility of listric fault models with the geomorphology of these structures, we interpret each fault as passing from a gently dipping $\left(<20^{\circ}\right)$, planar ramp at depth to a listric fault plane that attains steeper $\left(>50^{\circ}\right)$ dips in the shallow subsurface. Slip rate estimates from multiple terrace levels along each structure yield consistent results for each fault zone and match previous rate estimates. Integration of available subsurface data also lends validation to our interpretation and suggests some degree of control of preexisting basin architecture on the current geometry of active thrusting in the Mackenzie Basin.

\section{Study Area}

\subsection{Regional Setting and Neotectonics of the Mackenzie Basin}

[6] The Ostler and Irishman Creek faults are located in the intermontane Mackenzie Basin east of the central
Southern Alps of New Zealand (Figure 1). The faults represent discrete zones of active thrusting in a broad area of distributed deformation inboard of the plate boundary between the obliquely colliding Pacific and Australian plates. Two thirds of the $\sim 38 \mathrm{~mm} / \mathrm{yr}$ of relative motion between these plates [DeMets et al., 1994] manifests as oblique convergence along the plate-bounding Alpine Fault [Norris and Cooper, 2001], with the remainder absorbed by structures east of the Southern Alps [Pearson et al., 1995; Tippett and Hovius, 2000]. The Ostler fault zone represents a NNE striking zone of east directed thrusting, characterized by numerous, complex, and highly segmented surface ruptures showing dominantly west-side-up displacements. In contrast, the Irishman Creek fault zone to the northeast strikes NE-ENE and displays primary southeast-side-up scarps along northeast striking fault segments. Like the Ostler fault, surface ruptures along the Irishman Creek fault zone are highly segmented and exhibit complex and sinuous surface traces. On the basis of a lack of consistent lateral offsets of well-preserved paleochannels on outwash surfaces cut by each fault zone, slip on both fault zones is interpreted to lack any significant component of oblique slip. Each structure is thus considered a pure thrust [Read, 1984; Davis et al., 2005]. For this study, we concentrate on off-fault deformation in the hanging wall of each fault zone, where highly asymmetric anticlinal warping results in continuous, progressively tilted backlimbs with wavelengths up to several kilometers [Davis et al., 2005].

[7] Bedrock exposed in the ranges surrounding the Mackenzie Basin is predominantly Mesozoic greywacke of the Torlesse terrane and its low-grade metamorphic equivalent. Although limited in its exposure throughout the basin, a sequence of Late Cretaceous-Miocene sediments [Long et al., 2003; E. M. Chetwin and T. A. Stern, manuscript in preparation, 2006] and Plio-Pleistocene conglomerates of the Kurow group [Mildenhall, 2001] rest unconformably above Torlesse basement rocks. Seismic and gravity surveys in the vicinity indicate the prevalence of Tertiary sediments throughout the Mackenzie Basin, despite local thickness variations and discontinuities due to ongoing faulting [Long et al., 2003; Chetwin and Stern, manuscript in preparation, 2006; S. Kleffmann and T. A. Stern, manuscript in preparation, 2006]. Similar in character to Kurow group deposits, a series of Late Quaternary fluvioglacial sediments blankets much of the basin interior. Available geophysical data constrain the total thickness of Cenozoic sediments throughout the Mackenzie Basin to less than $2 \mathrm{~km}$ [Long et al., 2003].

[8] Published differential uplift rate estimates for the Ostler and Irishman Creek fault zones are based primarily on vertical separations of offset geomorphic features and range from 0.4 to $1.0 \mathrm{~mm} / \mathrm{yr}$ [Blick et al., 1989; Read and Blick, 1991; Davis et al., 2005] and $0.6 \mathrm{~mm} / \mathrm{yr}$ [Fox, 1987; Barrell and Cox, 2003], respectively. Similar or slightly higher rates of geodetically observed deformation occur along segments of the Ostler fault as elastic strain or aseismic folding [Blick et al., 1989]. Such deformation mimics the overall structure of the deformed hanging wall but occurs without detectable vertical displacement across the fault. Trenching along northern segments of the Ostler fault zone however, suggests that major segments of this fault zone rupture coseismically, with major paleoseismic 


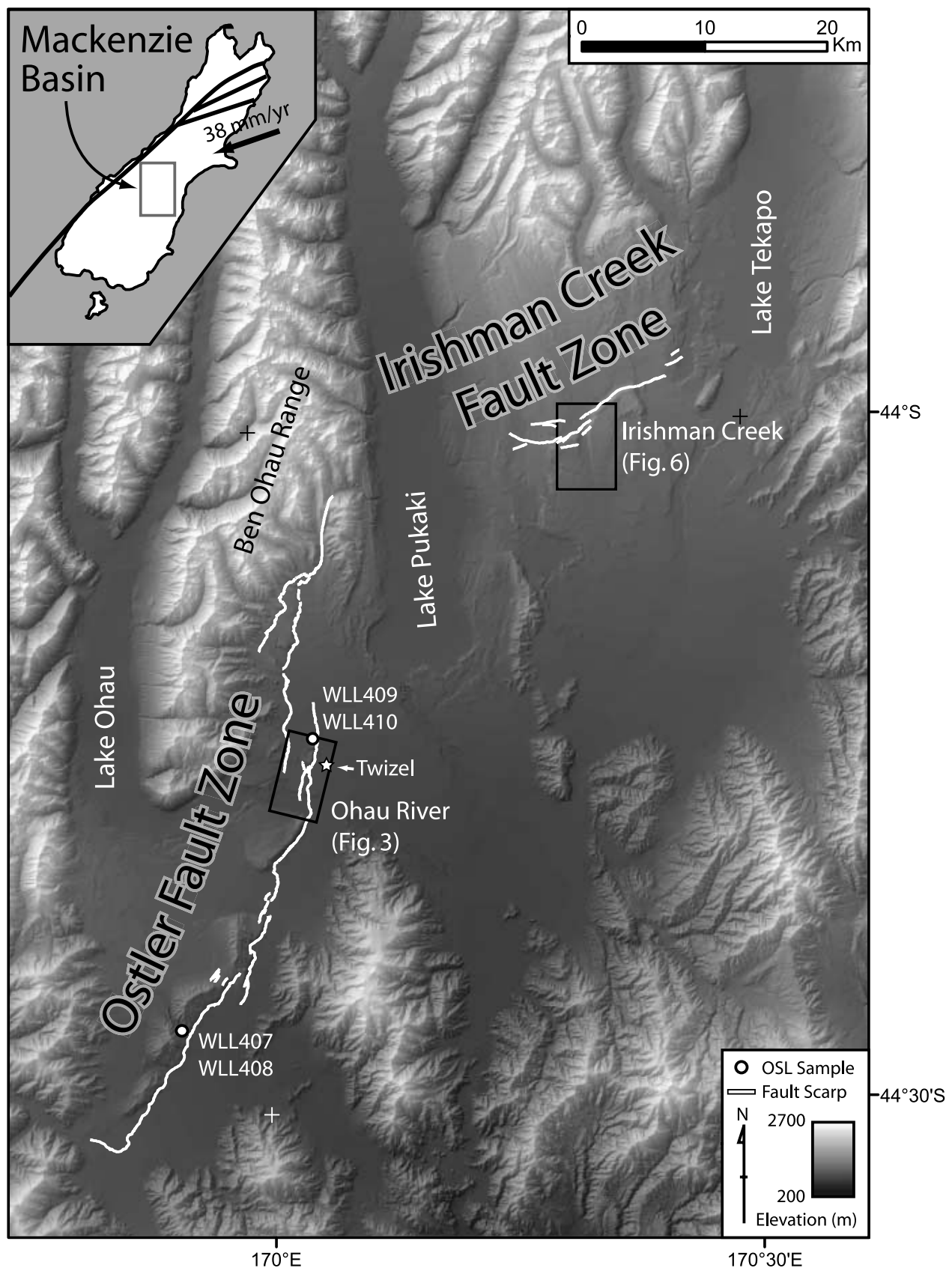

Figure 1. Regional overview of the Mackenzie Basin showing active fault scarps along the Ostler and Irishman Creek fault zones and OSL sample numbers and locations. Inset shows general tectonic setting of southern New Zealand, as well as the Alpine Fault plate boundary.

events occurring at $\sim 3500$ and $\sim 7000 \mathrm{ka}[$ van Dissen et al., 1994]. Preliminary interpretation of new paleoseismic trench opened by the authors across the central Ostler fault also reveals evidence for multiple coseismic displacements since the Late Pleistocene. For the Irishman Creek fault, McSaveney [1991] reports a $\sim 1300 \mathrm{kyr}$ recurrence interval for paleoseismic based on weathering-rind thickness measurements on rockfall deposits adjacent to the frontal scarp. Along both fault zones, continuous 1- to 4-m-high scarps abutting major surface traces may represent offsets during the most recent seismic event. If so, such features indicate the potential for continuous rupture along each fault zone as a whole and lends support to the notion that individual surface traces may represent kinematically linked fault segments at depth [Davis et al., 2005].

\subsection{Geomorphology and Quaternary Chronology}

[9] Multiple generations of fluvial terraces and outwash surfaces reflecting at least three Late Pleistocene glaciations dominate the surficial geology of the Mackenzie Basin [Read, 1984; Blick et al., 1989]. Major surfaces throughout the Mackenzie Basin correlate between individual drainages and are graded to moraines preserved in the adjacent highlands [Read, 1984; Maizels, 1989; Read and Blick, 1991]. 


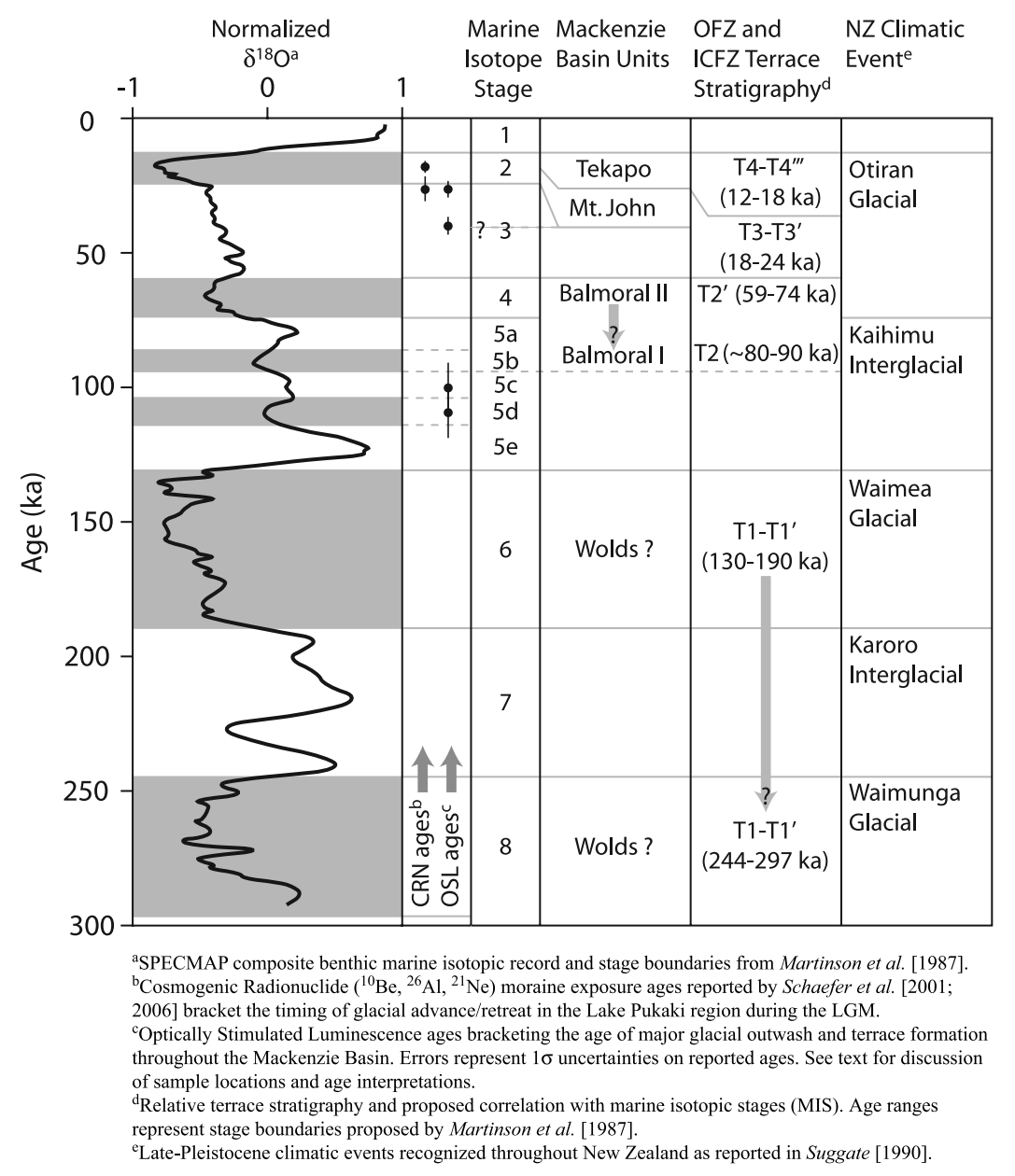

Figure 2. Terrace stratigraphy/Quaternary chronology for terraces along the Ohau River and Irishman Creek water gap. OSL ages from fluvial silts below a prominent T2 terrace folded over the Ostler fault suggest correlation of the Balmoral age association with Marine Isotope Stage 4 or $5 \mathrm{~b}$. The younger of two OSL dates from a T3 terrace along the southern Ostler fault zone yields a Mount John age compatible with cosmogenic exposure dating of moraines in the Lake Pukaki region by Schaefer et al. [2001, 2006]. See text for discussion.

Vertical downcutting by rivers incised into these surfaces has preserved flights of fluvial terraces perched above modern river valleys. Fluvial terraces forming the basis of this study originated as straths or cut terraces beveled into Tertiary bedrock or upper Quaternary outwash. Where visible, variable cover of coarse fluvial gravels ranging from several meters to tens of meters in thickness directly overlie strath surfaces. Terrace surfaces are pristine, relatively uneroded, and blanketed with a locally variable loess cover typically $<1 \mathrm{~m}$ in thickness [Maizels, 1989]. If we assume that these surfaces form with an initial geometry approximated by modern stream long profiles, terrace surfaces throughout the Mackenzie Basin represent ideal strain markers to record the kinematics of active deformation given their lateral continuity and the potential to date their formation [e.g., Lavé and Avouac, 2000; Thompson et al., 2002].

[10] Existing chronologies for Late Pleistocene geomorphic features in the Mackenzie Basin typically classify deposits and landforms according to four major age divisions. Originally categorized based on relative dating techniques and field relationships, geomorphic features are subdivided into the Wolds, Balmoral, Mount John, and Tekapo age associations, from oldest to youngest [Gair, 1967]. For this study, we adopt a similar classification scheme of four major terrace associations ( $\mathrm{T} 1-\mathrm{T} 4$, from oldest to youngest), noting that each contains several subdivisions and multiple terrace levels (Figure 2). Potentially resulting from complex response to changing hydrologic conditions specific to a given drainage $[$ Bull, 1990], terraces are often unpaired and the exact number of terrace treads present for a given age association varies locally. Successively younger terrace subdivisions are denoted using apostrophes, e.g., $\mathrm{T}^{\prime}$ or $\mathrm{T} 4^{\prime \prime}$.

[11] Chronologic constraints on the Tekapo and Mount John age divisions come from radiocarbon dates [Maizels, 1989] and cosmogenic exposure age dating of end moraines in the Lake Pukaki region [Schaefer et al., 2001, 2006]. These results bolster correlation with the Last Glacial Maximum or Otiran Glacial period in New Zealand [Suggate, 1990]. Association of the Balmoral and Wolds Formations with older Late Quaternary stratigraphic subdivisions in New Zealand, however, is based purely on tentative climatic correlation with the marine isotopic record 
Table 1a. Luminescence Dating Results: Water and Radionuclide Contents ${ }^{\mathrm{a}}$

\begin{tabular}{|c|c|c|c|c|c|c|c|c|}
\hline Sample $^{\mathrm{b}}$ & $\begin{array}{l}\text { Depth, } \\
\mathrm{m}\end{array}$ & $\begin{array}{c}\text { Water } \\
\text { Content } \delta^{\mathrm{c}}\end{array}$ & $\begin{array}{c}\text { U From }{ }^{234} \mathrm{Th}, \\
\mu \mathrm{g} / \mathrm{g}\end{array}$ & $\begin{array}{c}\text { U From }{ }^{226} \mathrm{Ra}, \\
{ }^{214} \mathrm{~Pb}, \\
{ }^{214} \mathrm{Bi},{ }^{\mathrm{d}} \\
\mu \mathrm{g} / \mathrm{g}\end{array}$ & $\begin{array}{c}\text { U From } \\
\mu \mathrm{g} / \mathrm{g}\end{array}$ & $\begin{array}{c}\text { Th From }{ }^{208} \mathrm{Tl}, \\
{ }^{212} \mathrm{~Pb}, \\
{ }^{228} \mathrm{Ac}, \\
\mu \mathrm{g} / \mathrm{g}\end{array}$ & $\mathrm{K}, \%$ & Field Code \\
\hline WLL407 & 2.3 & 1.222 & $2.85 \pm 0.28$ & $2.21 \pm 0.04$ & $2.51 \pm 0.23$ & $9.76 \pm 0.13$ & $1.86 \pm 0.04$ & OST-303-2 \\
\hline WLL408 & 2 & 1.116 & $4.19 \pm 0.46$ & $2.31 \pm 0.05$ & $2.77 \pm 0.42$ & $11.45 \pm 0.17$ & $2.13 \pm 0.05$ & OST-303-1 \\
\hline WLL409 & 5.5 & 1.134 & $3.81 \pm 0.47$ & $3.08 \pm 0.05$ & $3.14 \pm 0.45$ & $13.33 \pm 0.19$ & $1.64 \pm 0.04$ & OST-308-1 \\
\hline WLL410 & 5.5 & 1.127 & $3.88 \pm 0.33$ & $3.33 \pm 0.05$ & $3.59 \pm 0.29$ & $13.68 \pm 0.17$ & $1.75 \pm 0.04$ & OST-308-2 \\
\hline
\end{tabular}

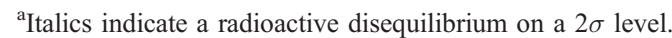

${ }^{\mathrm{b}}$ Sample preparation and measurements at the Luminescence Dating Laboratory, School of Earth Sciences, Victoria University, Wellington, New Zealand.

${ }^{\mathrm{c}}$ Ratio wet sample to dry sample weight. Errors assumed $50 \%(\delta-1)$.

${ }^{\mathrm{d}} \mathrm{U}$ and $\mathrm{Th}$ contents are calculated from the error weighted mean of the isotope equivalent contents.

[Martinson et al., 1987] without geochronologic control. Here, we present the results of optically stimulated luminescence (OSL) dating of fluvial silts (Tables $1 \mathrm{a}$ and $1 \mathrm{~b}$ ) that bracket the age of terrace formation for both Balmoral and Mount John age associations and extend existing chronologies beyond the Last Glacial Maximum.

[12] OSL dating of Quaternary sediments may accurately reflect true depositional ages provided that the material being dated was sufficiently exposed to sunlight during transport prior to deposition [e.g., Duller, 1996; Aitken, 1998]. As such, care was taken to sample only silts and finegrained sands suggestive of overbank deposition in a shallow, quiescent fluvial environment. Samples WLL409 and WLL410 come from a layer of interbedded silts and sands lying unconformably beneath $\sim 10 \mathrm{~m}$ of outwash gravel in a prominent Balmoral (T2) terrace just north of the Ohau River (Figure 1). Both samples were collected from the same stratigraphic horizon and overlap in age at the $95 \%$ confidence level (Tables $1 \mathrm{a}$ and $1 \mathrm{~b}$ and Figure 2). The weighted mean and standard error for these ages used in subsequent slip rate calculations is $104.9 \pm 6.3 \mathrm{ka}$. Given the position of this unit beneath the strath-capping gravels, we consider this age a maximum for the older Balmoral (T2) terrace association, thus indicating potential correlation with Marine Isotope Stage $5 b$ or 4 (Figure 2).

[13] Samples WLL407 and WLL408 represent interbedded silts and sands collected from a $\sim 3 \mathrm{~m}$ section of gravel on a Mount John strath at the southern end of the Ostler fault zone (Figure 1). Despite only $30 \mathrm{~cm}$ of stratigraphic separation, calculated OSL ages for these two samples show an age difference of $\sim 13 \mathrm{kyr}$ (Tables 1a and 1b). This age discrepancy could reflect the radioactive disequilibrium detected for these samples, although the older age of the lower sample (WLL408) may result from only partial exposure to light prior to deposition. Given the similarity of the younger OSL date for sample WLL407 $(26.7 \pm 2.5 \mathrm{ka})$ to cosmogenic exposure dating of probable Mount John moraines at Lake Pukaki, we use the $26.5 \pm 4 \mathrm{ka}$ age reported by Schaefer et al. [2001] in subsequent slip rate calculations for Mount John terraces. Similarly, slip rate calculations for Tekapo terraces utilize the reported date of $17.4 \pm 1.0 \mathrm{ka}$ [Schaefer et al., 2006] for moraines of probable Tekapo affinity. This date is generally consistent with radiocarbon ages for Tekapo landforms as summarized by Maizels [1989]. Similar to terrace ages deduced from dating material deposited on top of the strath, moraine exposure dates reflect minimum ages given the potential for erosion and cover of moraine boulders subsequent to deposition [Putkonen and Swanson, 2003].

[14] General agreement between terrace ages bracketed using OSL dating techniques, moraine exposure ages [Schaefer et al., 2001, 2006], and climate proxies reflecting changes in global ice volume [Martinson et al., 1987] (Figure 2), is consistent with hypothesized climatic control of terrace genesis in New Zealand [e.g., Formento-Trigilio et al., 2003; Litchfield and Berryman, 2005] and elsewhere [e.g., Molnar et al., 1994]. If so, active folding and differential uplift due to faulting serves to locally amplify the effects of incision [Nicol and Campbell, 2001; Pan et al., 2003], in response to regional variations in sediment supply and discharge ultimately that are driven by climate change [Hancock and Anderson, 2002].

\section{Thrust-Related Folding in the Mackenzie Basin 3.1. Ostler Fault Zone: Ohau River Terraces}

[15] The Ohau River crosses the northern end of the central segment of the Ostler fault just south of the town of Twizel (Figure 1). There, multiple flights of Late Pleistocene and Early Holocene terraces are cut into Tertiary bedrock and Quaternary outwash deposited from glaciers inhabiting the depression now occupied by Lake Ohau

Table 1b. Luminescence Dating Results: Measured $a$ Value and Equivalent Dose, Cosmic Doserate, Total Doserate, and OSL Age

\begin{tabular}{lccccrcr}
\hline Sample $^{\mathrm{a}}$ & $a$ Value & \multicolumn{1}{c}{$\mathrm{D}_{\mathrm{e}}, \mathrm{Gyr}$} & $\mathrm{dD}_{\mathrm{c}} / \mathrm{dt}{ }^{\mathrm{b}} \mathrm{Gyr} / \mathrm{ka}$ & $\mathrm{dD} / \mathrm{dt}, \mathrm{Gyr} / \mathrm{ka}$ & OSL Age, $^{\mathrm{c}} \mathrm{ka}$ & Age $^{\mathrm{d}}$ & Field Code \\
\hline WLL407 & $0.047 \pm 0.005$ & $88.8 \pm 5.2$ & $0.1673 \pm 0.0084$ & $3.32 \pm 0.22$ & $26.7 \pm 2.5$ & Mount John & OST-303-2 \\
WLL408 & $0.067 \pm 0.007$ & $183.6 \pm 8.4$ & $0.1742 \pm 0.0087$ & $4.57 \pm 0.18$ & $40.2 \pm 2.7$ & Mount John & OST-303-1 \\
WLL409 & $0.055 \pm 0.005$ & $432.9 \pm 29.3$ & $0.1123 \pm 0.0056$ & $3.96 \pm 0.18$ & $109.5 \pm 9.0$ & Balmoral & OST-308-1 \\
WLL410 & $0.060 \pm 0.007$ & $428.6 \pm 31.7$ & $0.1123 \pm 0.0056$ & $4.27 \pm 0.20$ & $100.4 \pm 8.8$ & Balmoral & OST-308-2 \\
\hline
\end{tabular}

${ }^{a}$ Sample preparation and measurements at the Luminescence Dating Laboratory, School of Earth Sciences, Victoria University, Wellington, New Zealand.

${ }^{\mathrm{b}}$ Contribution of cosmic radiation to the total doserate, calculated as proposed by Prescott and Hutton [1995].

'Samples WLL407 and WLL408 showed a radioactive disequilibrium and the given ages are corrected accordingly. Because the level of disequilibrium over time is unknown, this age is only an estimate and may not reflect true depositional age.

${ }^{\mathrm{d}}$ Age designation based on previously defined Quaternary chronologies. See text for discussion. 


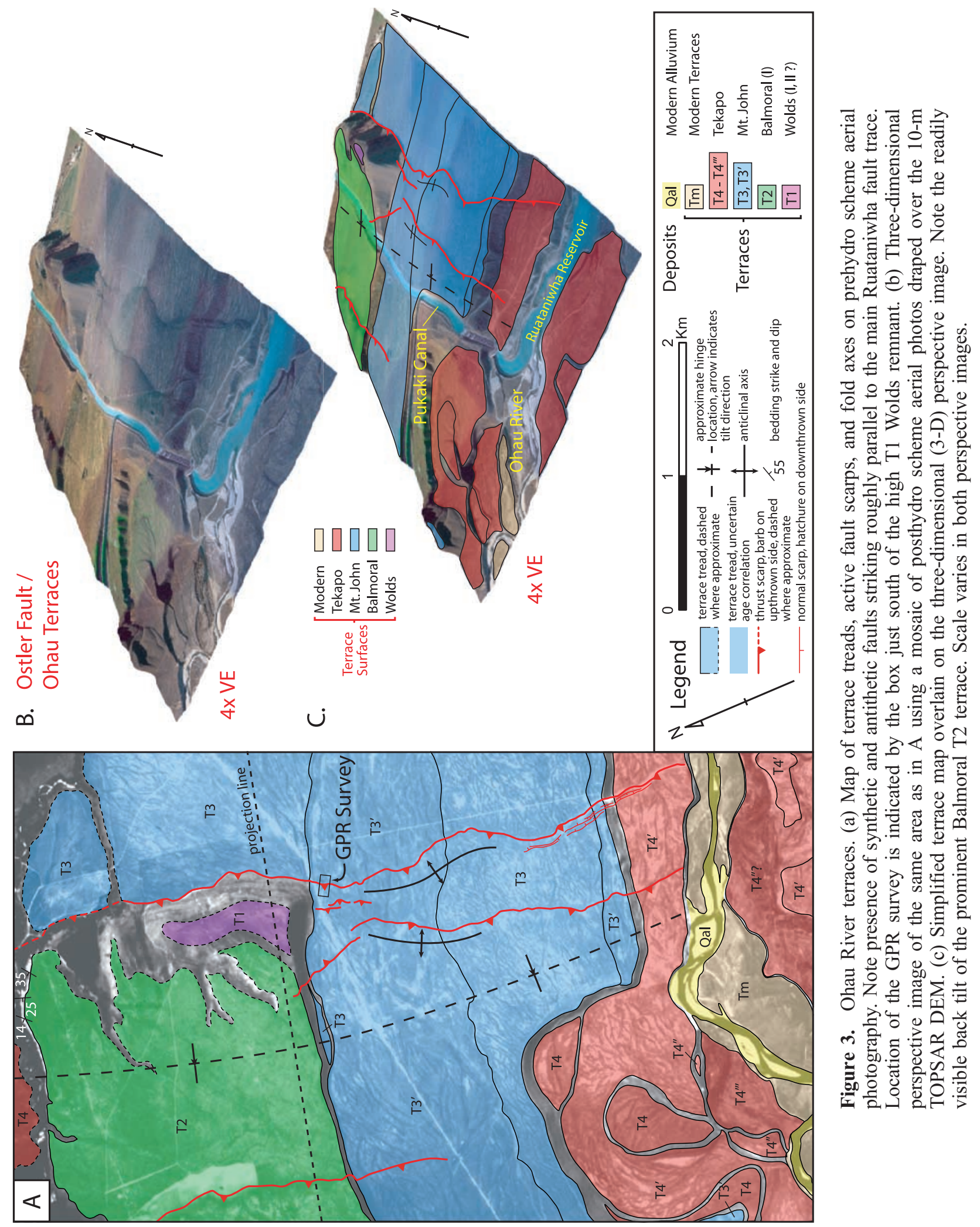



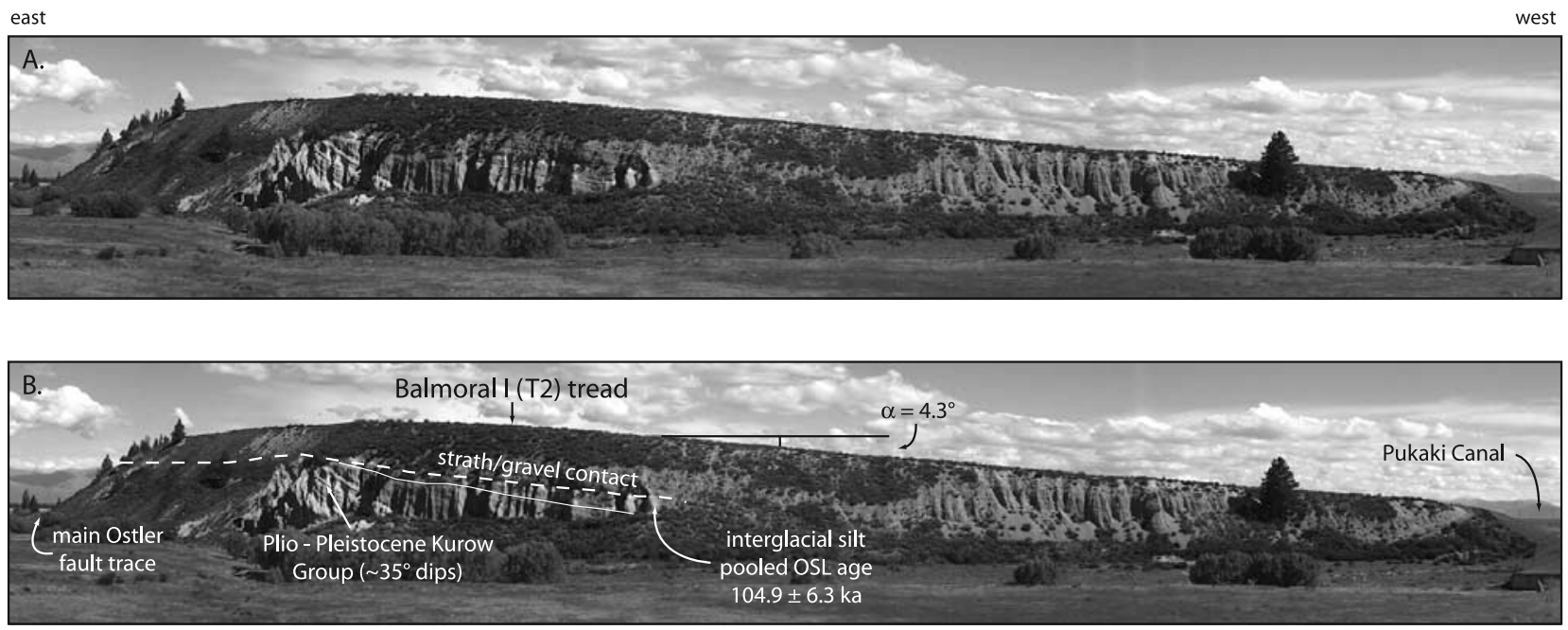

Figure 4. (a) Photograph at the northern end of the prominent Balmoral T2 terrace along the Ostler fault zone. View is roughly to the south. Maximum height of the terrace tread above the modern stream is $\sim 70 \mathrm{~m}$. (b) Interpretation of the same photograph showing the $\sim 15 \mathrm{~m}$ of strath-capping gravels and $4.3^{\circ}$ back tilt as measured from topographic surveying. The underlying strath is composed mostly of Tertiary bedrock with a distinct layer of interglacial silts sampled for OSL dating directly underlying the terrace gravels.

(Figures 1 and 3). The modern Ohau River incises these terraces and flows roughly perpendicular to the Ostler fault where it intersects the Ruataniwha reservoir. The reservoir is also fed by the Pukaki/Ohau canal as part of the Waitaki hydroelectric generation project throughout the south central South Island. Mapping of terrace treads, fault scarps, and fold axes was done using both prehydroscheme and posthydroscheme aerial photography (1:40,000 and $1: 10,000$, respectively) and shows the general pattern of older terrace surfaces stepping south down to the modern river (Figure 3). Terrace treads for Mount John and Tekapo age surfaces are largely uneroded and display intricate texturing with paleooutwash channels and rills (Figure 3a).

[16] Where it crosses the Ohau terraces, the Ostler fault zone consists of several roughly parallel segments striking $\sim 015^{\circ}$. The main, easternmost trace, termed the Ruataniwha fault by Blick et al. [1989], sits at the base of low hills to the north formed by uplifted and tilted Balmoral and probable Wolds age straths beveled into Tertiary bedrock (Figure 3a). Farther south, this fault cuts all but modern terrace levels and is paralleled by a subsidiary forethrust in its hanging wall. Deemed the "Y" fault by Blick et al. [1989], this fault terminates to the north along a prominent back thrust that cuts the higher Balmoral T2 terrace. Numerous scarps with apparent normal offsets up to several meters form a crestal graben system in the hanging wall of the Ruataniwha fault where it cuts Mount John and Tekapo surfaces just north of the reservoir.

[17] Folding of the Ohau River terraces is characterized by broad, continuous, and planar backlimbs (Figure 4) that grade into flat terrace segments roughly parallel to the modern river. This transition defines the hinge zone or active axial surface that trends roughly parallel to the main Ostler fault trace $\sim 1 \mathrm{~km}$ from the frontal scarp along the Ruataniwha segment (Figure 3). Except where it crosses a major inset Mount John outwash channel (T3', Figure 3a), folding in the hanging wall of the Ostler fault zone is highly asymmetric and generally occurs with little forelimb development other than that preserved over the frontal scarp. Along both the Ruataniwha and Y fault traces, folding over this inset outwash channel changes along strike from broad, anticlinal warping to roughly planar back tilted segments to the south [Read, 1984; Blick et al., 1989], potentially reflecting changes in the depth of unconsolidated Quaternary outwash [Davis et al., 2005].

[18] Profiles along the tops of terrace treads were surveyed using a Trimble 4700 differential GPS with centimeter vertical and horizontal precision. Survey points are projected perpendicular to the axial surface trend (Figure 5) and reveal progressive tilting of successive terrace levels. Terrace profiles generally reflect elevations along the tread/riser break for each surface. Reported heights reflect removal of the $\sim 0.4^{\circ}$ gradient Ohau River before it enters the Ruataniwha Reservoir (Figure 5a). Given the overall parallelism between untilted terrace segments and the linear fit through stream profile points, we consider this regression a reasonable local approximation to both the modern long profile and river gradients during terrace formation.

[19] Along this relatively short reach and for the lower T4 terrace surface, we supplemented our survey data with profiles from a 10-m TOPSAR digital elevation model (DEM) with a vertical resolution of less than $2 \mathrm{~m}$. DEM profiles were tied into survey measurements through repeat surveying of known benchmarks and were adjusted accordingly for elevation offsets.

[20] Linear regressions through the planar segments of fold backlimbs allow measurement of tilts associated with folding over the Ostler fault zone (Figure 5b). For the prominent Balmoral T2 surface, profiles along the southern tread/riser slope break reveal a $2.4^{\circ}$ tilt to the west before the surface terminates against the $\mathrm{Y}$ fault back thrust and abuts a probable Wolds T1 remnant. Profiles along the same T2 surface to the north are at a lower elevation but reveal a 

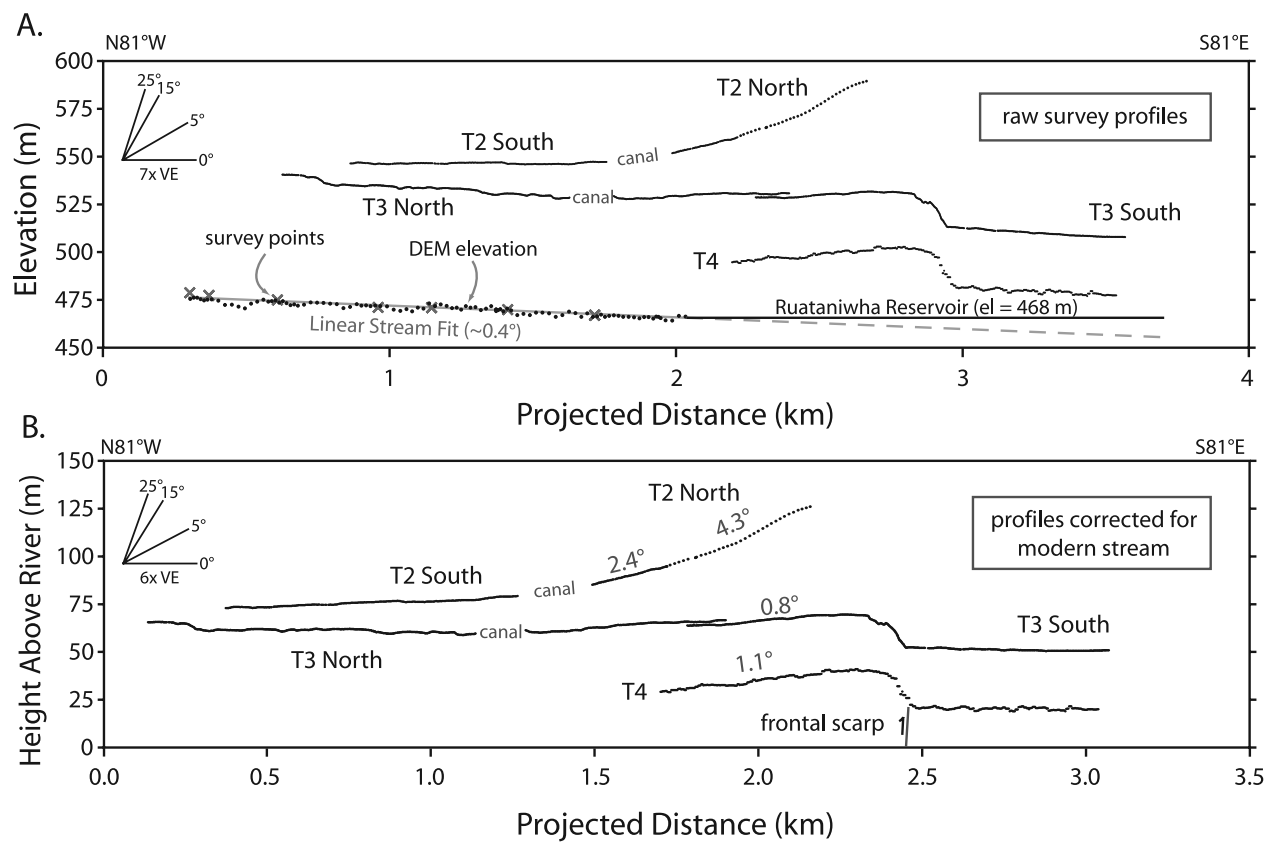

Figure 5. Ohau River terrace profiles. (a) Raw survey measurements are projected approximately perpendicular to the synclinal axial surface trend. Survey points along the Ohau River are augmented with elevations from a TOPSAR 10-m DEM. (b) Terrace heights above the Ohau River reflect removal of the $\sim 0.4^{\circ}$ linear fit to the long profile. Reported tilts reflect linear regressions (not shown) through planar portions of the folded backlimb. Survey points along the T2N terrace are adjusted in elevation for visual continuity with the same surface farther south.

continuous back tilt of $4.3^{\circ}$ away from the main Ostler fault trace (Figure 4). We thus include survey points along this surface labeled as T2 North on Figure 5 and adjust the elevation for visual continuity with the T2 surface to the south. Lower Mount John (T3) and Tekapo (T4) terrace surfaces show an apparent discrepancy between the degree of tilting $\left(0.8^{\circ}\right.$ and $1.1^{\circ}$, respectively) given their relative ages. Rather than errors associated with elevation measurement from the DEM, greater tilts for the younger Tekapo terrace may reflect along-strike variation in either the magnitude of fault slip or the direction of tilting. Similar scarp heights of $\sim 20 \mathrm{~m}$ across the Ruataniwha segment for both of these surfaces (Figure 5b), imply that the period of time between lateral beveling and incision of the Mount John and Tekapo surfaces may have been sufficiently short to outpace the recurrence interval for seismic events along this portion of the fault. If so, deformation of both surfaces reflects folding since formation of the Tekapo terrace, and slip rates calculated for both surfaces should reflect this age association.

\subsection{Irishman Creek Fault Zone}

[21] Located in the northern end of the Mackenzie Basin (Figure 1), the Irishman Creek water gap (Figure 6) represents a narrow canyon cut by the south flowing Irishman Creek through low-lying hills uplifted over the Irishman Creek fault zone. Fluvial terraces preserved along Irishman Creek are straths beveled into Tertiary bedrock and show the general pattern of older age surfaces stepping down to the modern river (Figure 6). The water gap itself is flanked on both sides by Wolds moraine [Gair, 1967; Maizels, 1989] deposited by Late Pleistocene glaciers inhabiting the Lake Tekapo and Pukaki valleys to the east and west, respectively. Unlike the Ohau River where it crosses the Ostler fault, differential uplift along the roughly northeast striking Irishman Creek fault zone faces up the drainage direction of Irishman Creek, resulting in a broad zone of aggradation and ponding immediately upstream of the fault zone. Across the fault zone, major changes in the character and pattern of Irishman Creek occur as it transitions from an anastamosing system of distributary channels to a single, braided thread upon entering the Irishman Creek gorge (Figure 6a). Mapping of terrace treads, fault scarps, fold axes, and active channels was done using 1:50,000 color orthophotos and 1:50,000 black and white aerial photography.

[22] Like the Ostler fault zone, surface traces of the Irishman Creek fault zone are highly segmented and consist of multiple strands striking $\sim 055^{\circ}$ at the northern end of the Irishman Creek water gap (Figure 6a). Where Irishman Creek crosses the fault, scarps at the base of uplifted hills to the south show a pronounced left step in an apparent transfer zone between overlapping fault segments. Scarps preserved farther south in the fault's hanging wall include a prominent back thrust cutting a Balmoral II (T2') terrace on the east side of the drainage and a subsidiary forethrust high on a Wolds T1 surface to the west (Figures 6a and 7).

[23] Terraces preserved in the hanging wall of the Irishman Creek fault display a similar pattern of deformation to the Ostler fault zone, where broadly tilted fold backlimbs flatten out to parallel the modern river downstream of the fault zone (Figure 7). Folding is highly asymmetric with short, abrupt forelimbs defining an anticlinal axis along the crest of the hanging wall trending parallel to the strike of major fault segments (Figure 6a). In contrast, the synclinal 

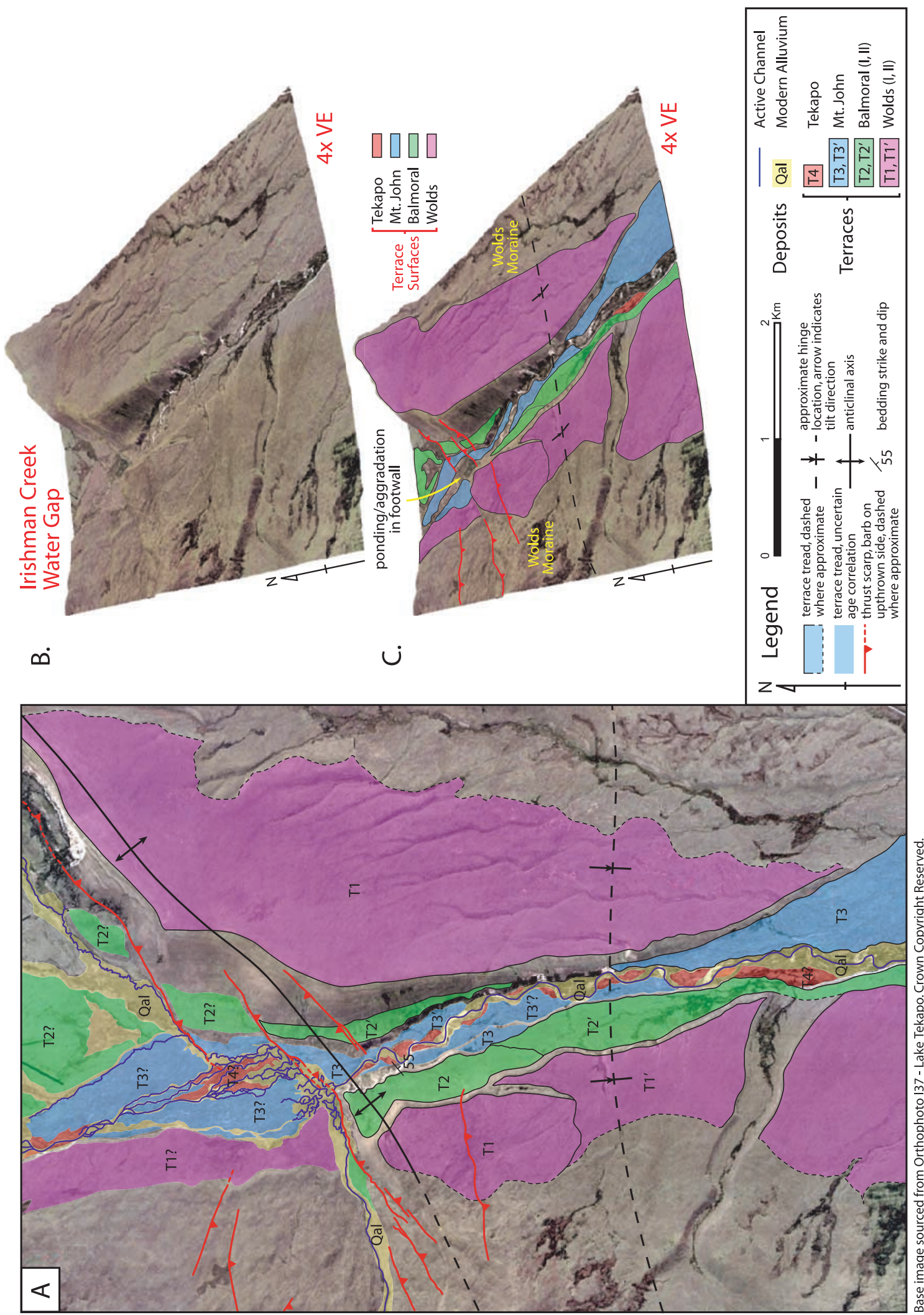

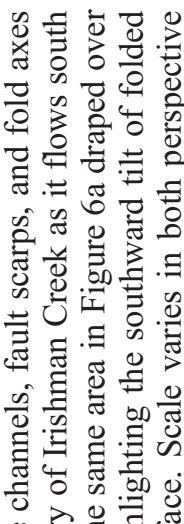

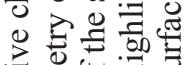

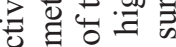

(5)

ॠ $\Xi . \Xi 3$

$\forall 0$

8 击

휴유

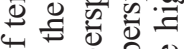

แ。

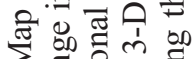

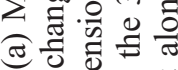

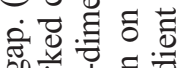

on

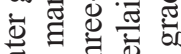

3 至客

40

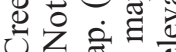

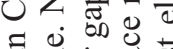

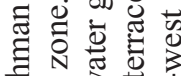

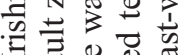

西本

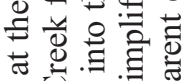

记语

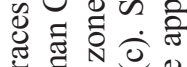

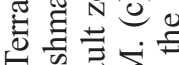

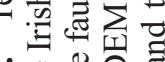

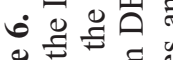

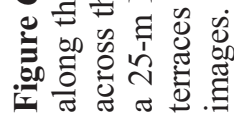



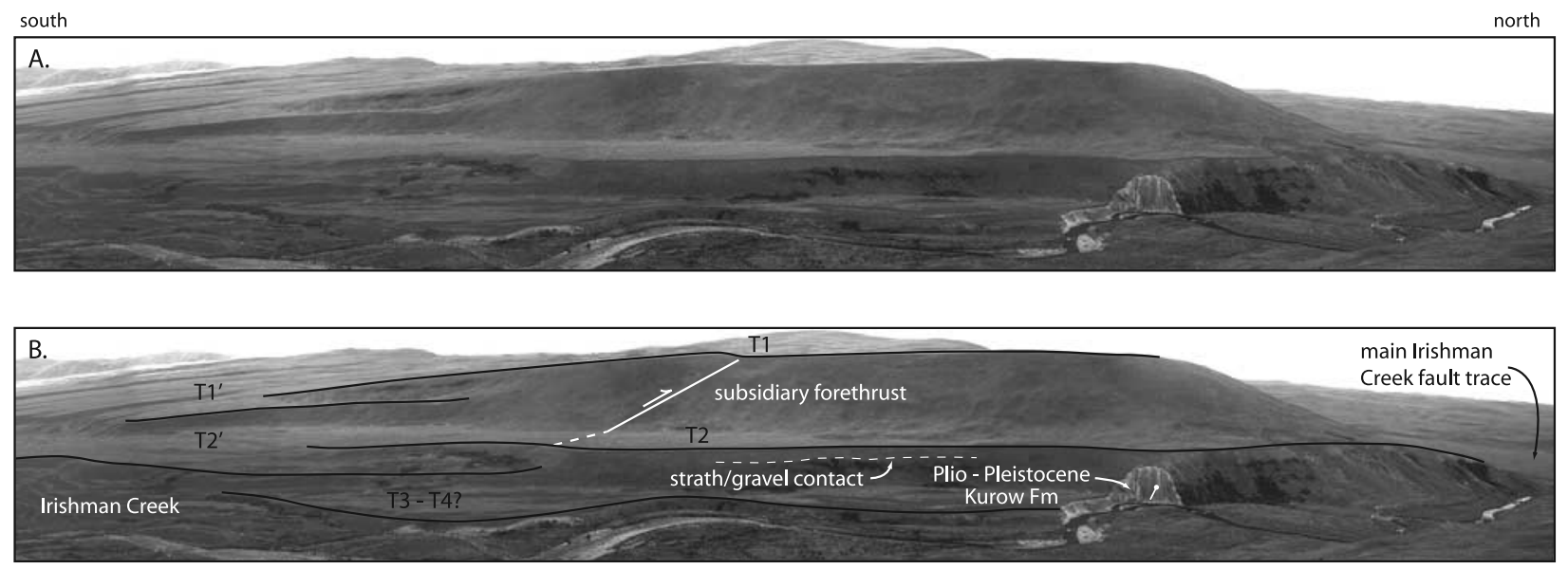

Figure 7. (a) Photograph showing strath terraces along the west side of the Irishman Creek water gap. View is roughly to the west. Maximum height of the Wolds T1 surface is $\sim 135 \mathrm{~m}$. (b) Interpretation of A showing correlation of various terrace levels. Note the synthetic thrust offsetting the T1 surface along the tilted backlimb.

axial surface defined by the transition from planar to tilted terrace surfaces trends roughly east-west, creating an apparent increase in the width of the tilted backlimb moving east along the fault zone (Figure 6a). Additionally, for terrace treads that correlate across the water gap, higher overall elevations on the east side of Irishman Creek imply some gradient in the magnitude of folding and thus fault slip from west to east along the Irishman Creek fault.

[24] Surveyed terrace profiles on the west side of the Irishman Creek water gap are projected perpendicular to the hinge zone or synclinal axial surface (Figure 8). Height along these profiles is recalculated following removal of elevations along the modern Irishman Creek long profile. A polynomial fit to the channel profile serves as a reasonable local approximation of stream gradients along a given reach, even in the presence of significant perturbations related to active faulting (Figure 8a). Overall parallelism between untilted terrace segments in the fault's hanging wall and the long profile suggests similar stream gradients during strath formation to the modern bedrock channel flowing through Irishman Creek gorge.

[25] Linear regressions through the roughly planar backlimbs of folded terraces along the Irishman Creek water gap display increasing tilts for progressively older surfaces

A.

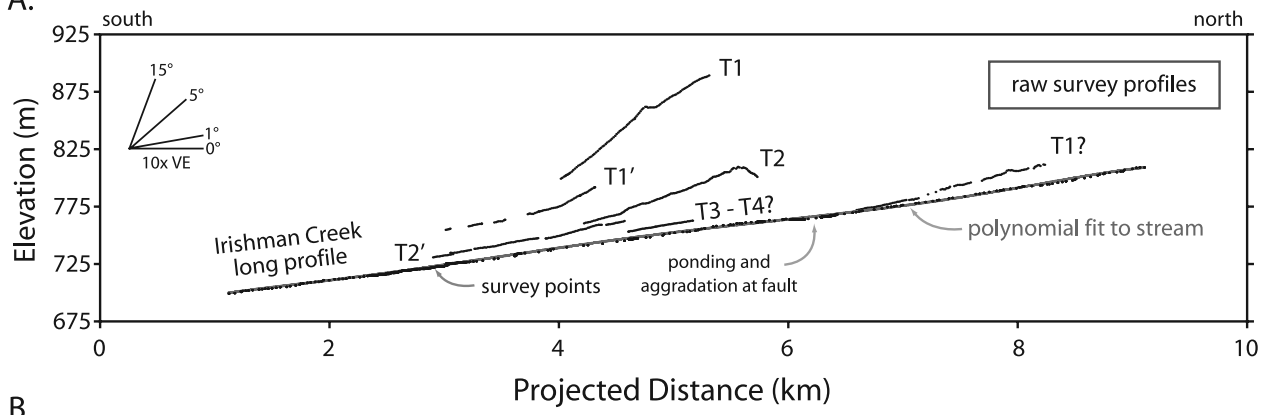

B.

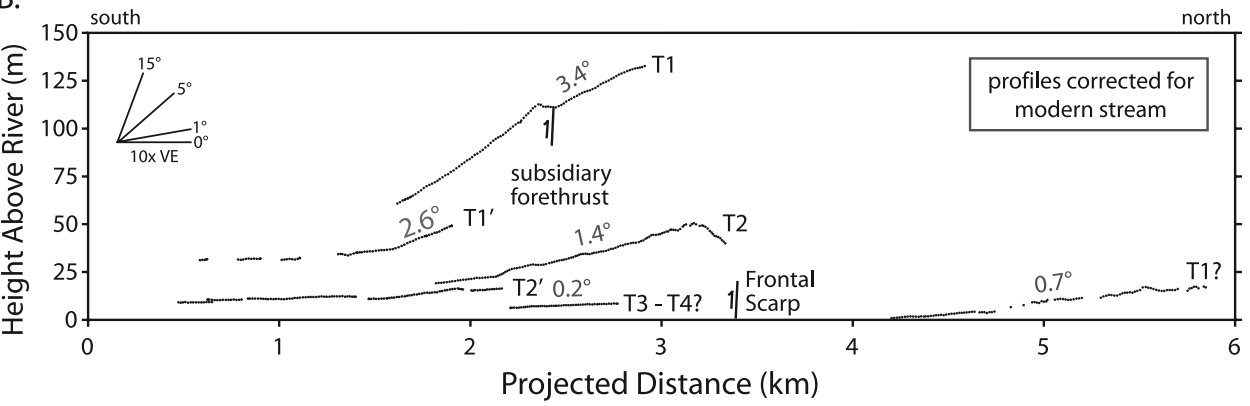

Figure 8. Irishman Creek terrace profiles. (a) Raw survey measurements are projected roughly perpendicular to the synclinal axial surface trend. Note the presence of decreased stream gradients at the zone of ponding and aggradation immediately upstream of the frontal scarp. (b) Terrace heights above Irishman Creek reflect removal of a polynomial fit to modern channel profile. Reported tilts reflect linear regressions through planar portions of the folded backlimb. 


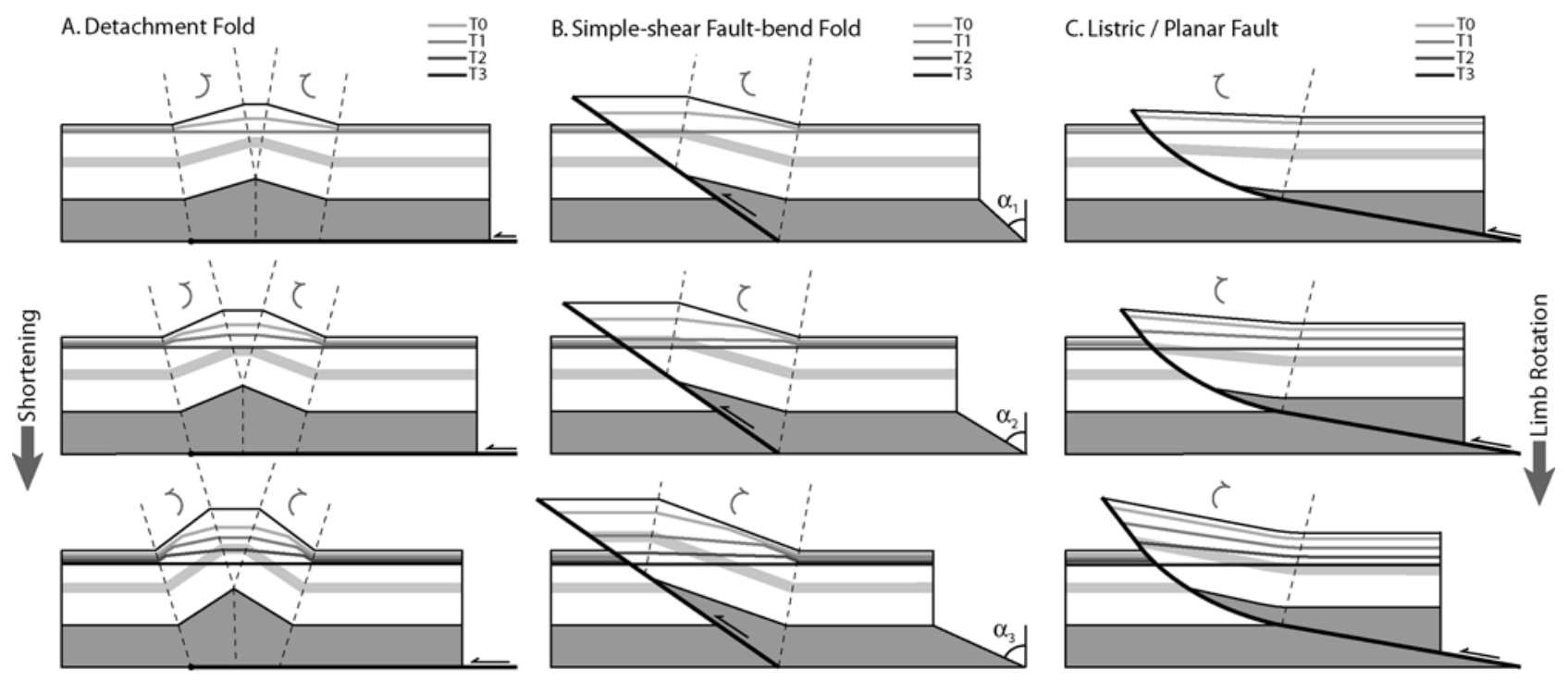

Figure 9. Simplified kinematic models for fault-related folding involving limb rotation. Each model shows progressive rotation of successively emplaced terrace levels from time T0 to T3. (a) Constant limb length detachment fold [Hardy and Poblet, 1994; Scharer et al., 2006]. Axial surfaces separate zones of progressive rotation in the absence of an emergent thrust. (b) Simple shear fault bend fold [Suppe et al., 2004]. Shear of an incompetent layer at depth from angles $\alpha_{1}$ to $\alpha_{3}$ results in progressive rotation of terrace segments separated by kinks from material fluxing through the active synclinal axial surface. (c) Listric/planar fault [Erslev, 1986; Seeber and Sorlien, 2000]. Increased shortening results in broad and smoothly continuous progressively rotated backlimbs in response to spatially variable uplift rates.

(Figure $8 \mathrm{~b}$ ). For the regression through the high $\mathrm{T} 1$ terrace, exclusion of points affected by the subsidiary forethrust yields a southward tilt of $3 \cdot 4^{\circ}$. Below that, a probable Wolds $\mathrm{T} 1^{\prime}$ terrace and a Balmoral I T2 surface show tilts of $2.6^{\circ}$ and $1.4^{\circ}$, respectively. Although $\sim 5 \mathrm{~m}$ lower than the upper $\mathrm{T} 2$ surface, a Balmoral II $\mathrm{T}^{\prime}$ terrace records the gradual transition from flat to tilted along the planar backlimb (Figure 8). Below that, an isolated terrace remnant of either Mount John or Tekapo affinity rests $\sim 6 \mathrm{~m}$ above the modern river and shows a slight, $0.2^{\circ}$ southward tilt.

\section{Listric Thrust Model}

\subsection{Progressive Limb Rotation}

[26] Like growth strata [e.g., Suppe et al., 1992], deformed fluvial terraces preserved over an active fault-related fold record the kinematic history of fold growth as slip accumulates on the underlying fault. Because various models for fault-related folding predict different patterns of surface deformation with progressive fault slip [Hardy and Poblet, 2005], the terrace record also affords the potential to differentiate among competing models for fold and fault growth [e.g., Scharer et al., 2006]. Before developing a model for terrace deformation over a listric thrust, we first demonstrate how deformed surface geometries produced over such structures are distinct from and can be used to distinguish among other models involving progressive limb rotation.

[27] Three relatively simple end-member models for fault-related folding involving limb rotation are detachment folding with constant limb length [Hardy and Poblet, 1994; Scharer et al., 2006], shear fault bend folding [Suppe et al., 2004], and folding above a listric thrust [Erslev, 1986;
Seeber and Sorlien, 2000] (Figure 9). In each of these models, successive terrace levels form along a transverse river flowing perpendicular to the fold orientation and deform passively with increased shortening. For simplicity, we neglect the effects of deformation during beveling of a given strath [Thompson et al., 2002], although temporal variations between periods of lateral erosion and vertical incision are likely to be high and are poorly constrained [Hancock and Anderson, 2002].

[28] Detachment folds develop where competent strata overly weaker material above a subhorizontal detachment horizon at depth. In the case of constant limb length detachment folding, fold amplification occurs through gradual tightening and limb rotation as slip accumulates along the underlying fault (Figure 9a) [e.g., Hardy and Poblet, 1994; Poblet and McClay, 1996]. Successively emplaced terraces developed over such structures display a similar pattern of increasing tilt for older surfaces in the absence of fault emergence at the fold front [Rockwell et al., 1988; Scharer et al., 2006]. Despite constant limb length, widening of the fold crest during fold growth requires material to pass through the axial surfaces bounding the fold, thereby creating a kink along each deformed terrace surface (Figure 9a). For shear fault bend folding [Suppe et al. 2004], tilting occurs through limb rotation associated with folding of competent strata over a weaker layer of finite thickness undergoing either simple or pure shear with progressive shortening (Figure 9b). Because the growth of these folds involves both limb rotation and limb lengthening by kink-band migration [Suppe, 1983], terraces deformed over shear fault bend folds show progressively tilted segments juxtaposed against domains of constant tilt reflecting migration of material through active axial surfaces. 


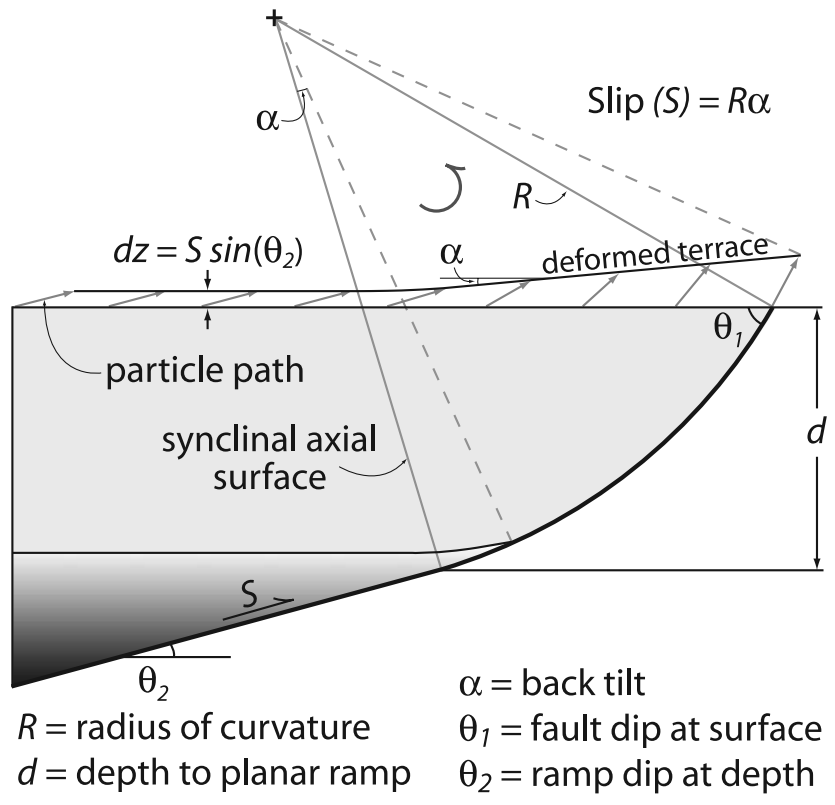

Figure 10. Geometric/kinematic model for terrace deformation over a listric thrust rooted at depth into a planar ramp. Particle paths outline the kinematic trajectories for a deformed terrace or horizontal unconformity with progressive slip. Rigid rotation over the listric fault segment results in backlimb tilting related to the magnitude of slip on the underlying thrust. For rigid rotation to occur, compression and extension are localized at the base and top of the backlimb, respectively [Erslev, 1986; Seeber and Sorlien, 2000], and flexural slip accommodates layer parallel shear along bedding planes. Continuity of slip across the synclinal axial surface results in differential uplift, $d z$, of the untilted terrace tread equal to the magnitude of slip times the sine of the ramp dip at depth. Geometric elements from topographic profiles and fault dip measurements are abbreviated as in the text and Appendix A.

[29] Idealized terrace patterns for detachment and shear fault bend folding are distinct from the smoothly continuous deformed surfaces predicted by hanging wall rotation over a curved or listric thrust, where no kinks occur across the active synclinal axial surface (Figure 9c). Over listric faults, folded terraces display broad, continuous, and progressively tilted backlimbs developed behind an emergent thrust at the fold front. If rooted into a planar ramp at depth, terraces will record a smooth transition between uniform rock uplift outside the fold to progressive tilting and rotation reflecting increasing fault dip along the listric segment.

[30] Because this pattern of differential uplift is incompatible with other fault-related folding models, we consider it diagnostic of deformation over a listric thrust. Similar patterns of limb rotation and terrace tilting, however, could develop over a multibend fault bend fold [Medwedeff and Suppe, 1997], although Seeber and Sorlien [2000] correctly note that a listric thrust represents a simpler approximation of this more complex variant. Additionally, high-magnitude flexural slip faulting within a simple fault bend fold could result in apparent limb tilting but would be readily distin- guishable from the above models by pervasive internal deformation of the folded straths in the hanging wall.

\subsection{Combined Geometric and Kinematic Model for Listric Thrust Faulting}

[31] Originally developed for normal faults [e.g., Wernicke and Burchfiel, 1982], models for listric faulting have seen application to the inversion of previously extensional fault systems [Seeber and Sorlien, 2000; Yamada and McClay, 2003] as well as to range-scale thrusts [Erslev, 1986; Erslev and Rogers, 1993; Abdrakhmatov et al., 2001]. To approximate surface deformation patterns associated with listric thrusting, we follow rigid rotation models developed by Erslev [1986] and Seeber and Sorlien [2000] for hanging wall deformation over a circular fault passing into to a planar ramp or décollement at depth (Figure 10). In this model, the listric fault segment forms the arc of a circle with a radius of curvature, $R$, and is tangential to a planar, dipping ramp at depth, $d$, in the deeper subsurface. As material translates over the fault with progressive slip, the displacements depicted in Figure 10 produce folding in the hanging wall while the footwall remains static. For the case of originally horizontal terrace surfaces and sedimentary layering, uniform rates of differential uplift over the planar ramp gradually increase across the active synclinal axial surface, resulting in a flat, uplifted segment that grades into the progressively tilted backlimb of the fold. Because motion across the axial surface is described by rotation along a circular arc, a necessary upward decrease in fault-parallel velocity above the listric portion of the fault requires localized compression and extension at the base and top of the backlimb, respectively [Erslev, 1986; Seeber and Sorlien, 2000]. Internal deformation within the hanging wall may be accommodated through layer parallel shear to conserve bed length [Bulnes and McClay, 1999; Seeber and Sorlien, 2000] and/or subsidiary faulting along the tilted backlimb [Erslev, 1986] without violating the geometric relationships prescribed by rigid rotation over a circular fault [Seeber and Sorlien, 2000]. Although depicted here with no forelimb (Figures 9c and 10), folding above a listric thrust can include the development of relatively steep, abrupt forelimbs through extension of the hanging wall block at the top of the backlimb, or through faulting associated with local footwall deformation near the emergent thrust [Erslev, 1986; Seeber and Sorlien, 2000].

[32] For the rigid rotation model presented in Figure 10, careful measurement of deformed terrace geometries through detailed topographic surveying enables estimation of fault slip and prediction of fault geometry at depth (Appendix A). Despite potential effects of internal deformation in the hanging wall on predictions of subsurface fault geometry and depth-to-detachment estimation [Bulnes and McClay, 1999; Yamada and McClay, 2003], the geometric considerations developed here provide a first-order estimate for fault geometry in the absence of subsurface seismic control. Although potentially significant in accurately describing the kinematics of listric thrusting, the amount of internal deformation may be small given the relatively low magnitude of slip and rotation associated with terrace deformation (See discussion below). 


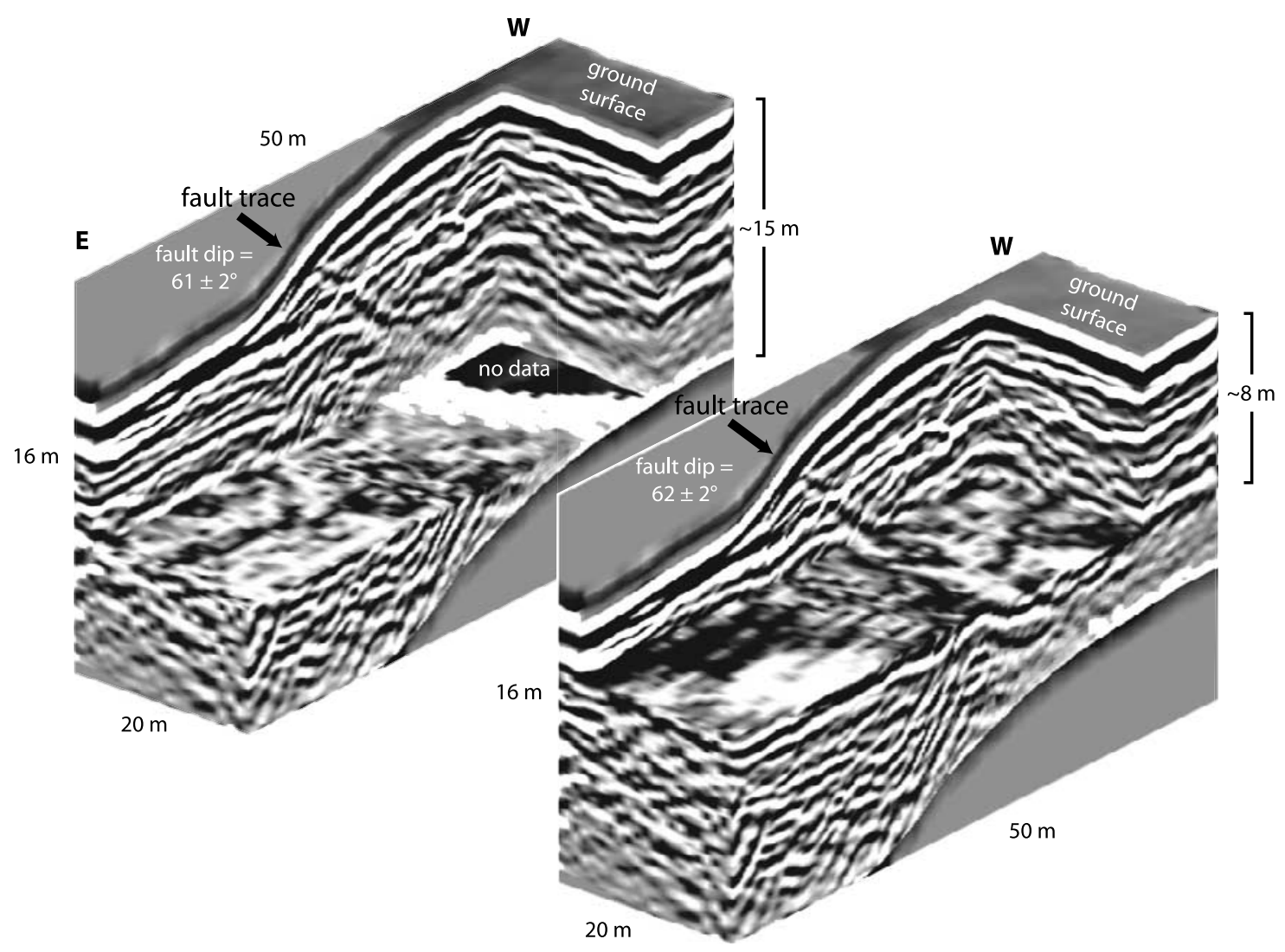

Figure 11. Ground-penetrating radar over active fault scarps along the Ruataniwha segment of the Ostler fault zone. Data for individual radar lines are compiled to create three-dimensional data cubes to facilitate visualization and measurement of the active fault trace. Two example cubes are shown with cutouts revealing active fault planes as prominent disruptions in the outwash stratigraphy overlain by unfaulted material at the surface. Mean fault dip from 14 measurements is $56 \pm 9^{\circ}(2 \sigma)$.

\subsection{Ground-Penetrating Radar}

[33] Given the dependence of fault slip rate estimates and predictions of subsurface fault geometry on accurate measure of fault dip in the shallow subsurface, we used groundpenetrating radar (GPR) across an active fault scarp along the Ostler fault zone to measure fault plane orientations and associated uncertainties. The details of GPR data acquisition, processing, and interpretation are presented in Appendix B. Compilation of closely spaced GPR profiles over the scarp into three dimensional data cubes (Figure 11) enhances visualization of individual fault planes and facilitates measurement of fault dip. Fault planes imaged with GPR (Figure 11) appear as discrete zones that disrupt the outwash stratigraphy and overlying loess/soil cover. Individual fault traces come within less than a meter of the surface and typically intersect the scarp face approximately one third of the total distance from the base of the scarp. Individual GPR profiles often reveal complex rupture patterns and the presence of multiple fault planes forming a given scarp. Additionally, the deformed stratigraphy imaged along individual profiles often reveals evidence of multiple rupture events as distinct colluvial wedges both cut by and abutting individual rupture surfaces [Nobes et al., 2005]. For the Ostler fault zone, measured fault dips across a $\sim 5 \mathrm{~m}$ scarp cutting a T3' surface north of the Ohau
River (Figure 10) yield a mean of $56 \pm 9^{\circ}(2 \sigma)$ from a total of 14 measured fault planes. This result stands in general agreement with the $50 \pm 9^{\circ}$ estimated by Davis et al. [2005] for the Ostler fault based on offsets of successive terrace levels.

\subsection{Monte Carlo Simulation}

[34] We use a Monte Carlo approach following Thompson et al. [2002] and Davis et al. [2005] to calculate uncertainties that are associated with fault slip rate estimates and fault geometry predictions computed from the listric thrust model. For the Monte Carlo simulation (Figure 12), probability distributions of each input parameter (e.g., fault dip) are sampled randomly over $10^{5}$ trials to generate a frequency distribution of the calculated output variable (e.g., slip rate). Reported values of predicted variables reflect the mode of the output histogram and the associated 95\% confidence intervals. For each simulation, the number of bins in the output histogram was chosen to minimize the bin interval while still retaining a clearly defined mode.

[35] The level of precision associated with our surveys is less than the "geomorphic noise," i.e., subtle elevation variations along the ground surface typically less than 1-2 dm, due to local differences in loess, soil, and vegetative cover. Although paleochannel rills with less than a meter 
Input Probability Distributions

backlimb regression (Tilt, $\alpha)$

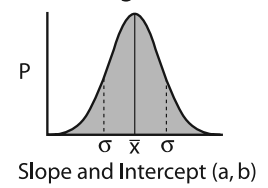

backlimb extrapolation (Width, W)

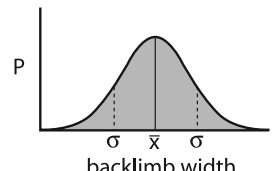

fault $\operatorname{dip}\left(\theta_{1}\right)$
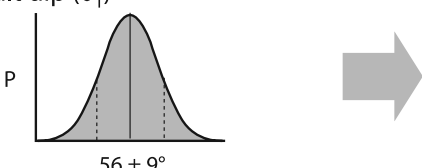

Histogram of Predicted Variable (100k trials)

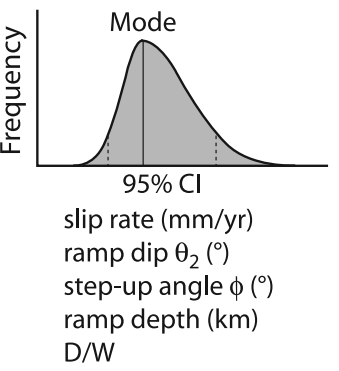

surface age Pooled mean $(n=2)$ for

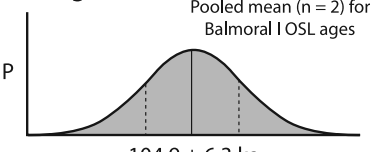

$104.9 \pm 6.3 \mathrm{ka}$

Inflection Distance (Appendix A)

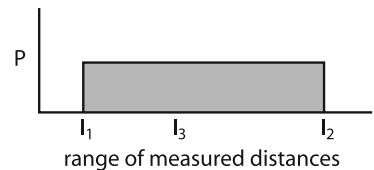

Figure 12. Schematic illustration of the Monte Carlo simulation for estimating slip rates and fault geometry at depth from topographic measurements of backlimb width and tilt, fault dip, and surface ages. The Monte Carlo routine draws from probability distributions of each input parameter to create a histogram of the predicted variable after a hundred thousand trials. Reported values represent the mode of the output histogram and the associated 95\% confidence intervals. Input probability distributions (left) include slope and intercepts of linear regressions used in tilt measurements, extrapolation of regressions to calculate backlimb width, fault dip, surface age, and the range of measured inflection distances from multiple terrace levels. See Appendix A for further discussion of these parameters and predicted variables output from the listric fault model.

of relief are ubiquitous on terraces throughout the Mackenzie Basin (Figure 3), survey measurements generally reflect minimal scatter with only subtle deviations from the linear regressions used to calculate tilts for planar backlimb surfaces. The measured mean and standard deviation of slopes and intercepts for regressions through survey data are used to create normal distributions for values of backlimb width and tilt (Figure 12). Similarly, we use the normal distribution to represent fault dip estimates and surface ages from OSL dating and cosmogenic work by Schaefer et al. [2001, 2006]. For measurements of the inflection distance, I (Appendix A), we use a uniform distribution reflecting the range in mea- sured positions of the synclinal axial surface from multiple terrace levels.

\section{Fault Slip Rates}

\subsection{Ostler Fault Zone}

[36] The general style of folding observed for the Ohau terraces is consistent with the surficial deformation patterns predicted by the listric thrust-related folding model (Figures $9 \mathrm{c}$ and 10). If tilting of the roughly planar backlimbs can be approximated by rigid rotation along a listric thrust fault, measured tilts (Figures $5 \mathrm{~b}$ and 13a) can be combined with backlimb width and surface ages to approximate slip rates along the underlying thrust (Appendix A). As outlined above, reported slip rates are given by the mode of output histograms and the associated $95 \%$ confidence intervals. Using the pooled OSL age of $104.9 \pm 6.3 \mathrm{ka}$ as a maximum for the Balmoral T2 surface yields minimum slip rate estimates of $1.1_{-0.1}^{+0.3} \mathrm{~mm} / \mathrm{yr}$ and $0.6_{-0.1}^{+0.2} \mathrm{~mm} / \mathrm{yr}$ for profiles along the northern and southern margins of this surface, respectively (Figure 13b). Given that the discontinuous nature of the T2S profile does not fully capture the magnitude of tilting along the main Ostler fault trace, we favor the higher of these two slip rate estimates despite lower elevations of the T2 surface to the north. For both the Mount John T3 and Tekapo T4 surfaces, using a minimum Tekapo age of $17.4 \pm 1.0 \mathrm{ka}$ [Schaefer et al., 2006] yields maximum slip rates of $1.3 \pm 0.2 \mathrm{~mm} / \mathrm{yr}$ and $1.7_{-0.2}^{+0.4} \mathrm{~mm} / \mathrm{yr}$, respectively (Figure 13b). A Mount John age of $26.5 \pm 4 \mathrm{ka}$ [Schaefer et al., 2001] reduces slip rate estimates for this surface to $0.8_{-0.2}^{+0.4} \mathrm{~mm} / \mathrm{yr}$.

[37] The vertical component of the preferred range of calculated slip rates $(\sim 1.1-1.7 \mathrm{~mm} / \mathrm{yr})$ slightly overestimates observed values of differential uplift for individual terrace surfaces across the frontal fault scarp. This discrepancy may reflect localized extension at the top of the fold backlimb where terraces roll over the abrupt forelimb [Erslev, 1986; Seeber and Sorlien, 2000], or erosion of higher terrace levels back from the frontal scarp. Additionally, the true magnitude of vertical separations across the fault may be subdued by tilting or subsidence driven by aggradation or nonstatic behavior of the footwall. Regardless, predicted vertical displacements fall within the range of uncertainty for reported slip rates and stand in general agreement with previous uplift rate estimates of up to $1 \mathrm{~mm} / \mathrm{yr}$ based on offsets of individual geomorphic surfaces [Blick et al., 1989; Read and Blick, 1991; Davis et al., 2005].

\subsection{Irishman Creek Fault Zone}

[38] Similar to the Ostler fault, the overall pattern of limb rotation for the Irishman Creek fault zone implied by progressively tilted terraces with broad, continuous backlimbs is consistent with the proposed model for folding over a listric thrust fault at depth (Figures 9c and 10). As such, measured backlimb tilts (Figures $8 \mathrm{~b}$ and 14a) are combined with backlimb width, surface ages, and fault dip estimates to calculate slip rates on the underlying thrust (Appendix A). In the absence of GPR over active scarps along the Irishman Creek fault zone, we use an estimate of fault dip from gravity surveying by E. M. Chetwin and T. A. Stern (manuscript in preparation, 2006) of $55 \pm 20^{\circ}(2 \sigma)$ for 
A.

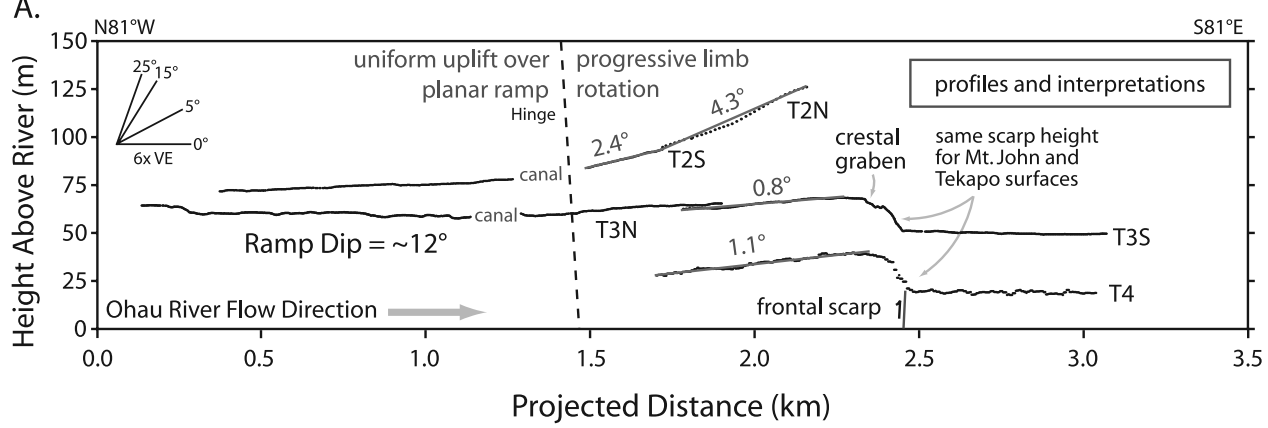

B.
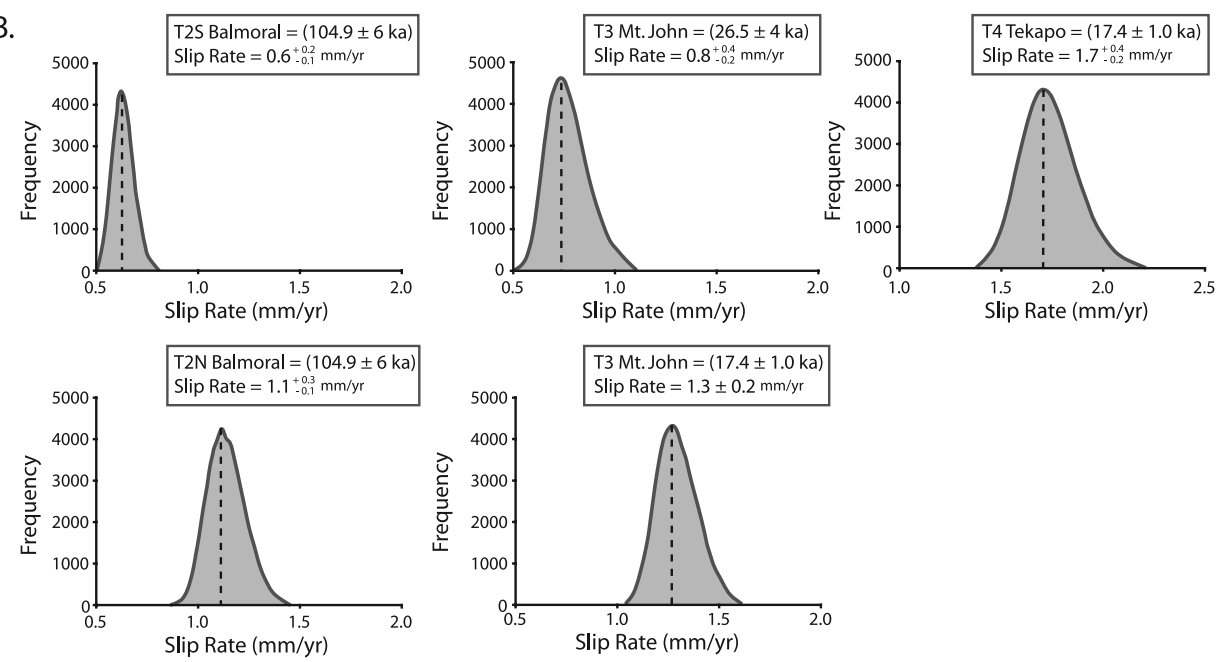

Figure 13. Ohau River terrace profiles and associated slip rates calculated from backlimb tilts. (a) Interpreted survey profiles corrected for height above the modern Ohau River. Note the progressive back tilt for hanging wall surfaces and the transition from planar to tilted terrace segments defining the hinge or axial surface. (b) Histograms of calculated slip rate output from the Monte Carlo simulation for each of the terraces in Figure 13a. Using the measured tilt from the T2N profile and a Tekapo age for the T3 Mount John terrace yields consistent slip rates of $\sim 1.1-1.7 \mathrm{~mm} / \mathrm{yr}$ for multiple terrace levels.

subsequent slip rate calculations. Although correlation with terraces farther downstream suggests a younger Balmoral II age for the T2' terrace [Fox, 1987; Barrell and Cox, 2003], using the older, Balmoral I age from OSL dating along the Ostler fault for the T2 surface yields a minimum slip rate of $0.7_{-0.1}^{+0.4} \mathrm{~mm} / \mathrm{yr}$ at the $95 \%$ confidence level (Figure 14b). Correlation of the lower T3 surface with either Mount John $(26.5 \pm 4 \mathrm{ka})$ or Tekapo $(17.4 \pm 1.0 \mathrm{ka})$ age associations [Schaefer et al., 2001, 2006] yields maximum slip rate estimates of $0.5_{-0.1}^{+0.3} \mathrm{~mm} / \mathrm{yr}$ and $0.7_{-0.1}^{+0.4} \mathrm{~mm} / \mathrm{yr}$, respectively.

[39] A major difference between the Irishman Creek water gap and the Ohau River terraces is the lack of continuity of terrace surfaces across the fault to the footwall of the Irishman Creek fault zone. Because thrusting faces up the flow direction of Irishman Creek, terraces north of the fault zone display a southward tilt of $0.7^{\circ}$ driven by footwall subsidence and/or active folding and are buried by sediment ponding against the hanging wall (Figure 14a). On the basis of the average height of this T1 surface outside the area affected by tilting, correlation with the high T1 Wolds surface allows measurement of backlimb width through projection of the hanging wall regression back to the undeformed footwall (Appendix A). We choose to correlate the footwall T1 terrace with the upper T1 surface (versus the lower $\mathrm{T}^{\prime}$ remnant) based on compatibility of the overall magnitude of slip implied by the $3.4^{\circ}$ tilt of this surface and the height of the untilted T1 terrace tread farther downstream (see discussion below). Using the $\mathrm{T} 1^{\prime}$ surface to project back to the undeformed footwall elevation results in a decrease in backlimb width of approximately $0.3 \mathrm{~km}$ and a corresponding reduction in calculated slip of approximately ten percent.

[40] Like the Ohau terraces, the vertical component of predicted slip rates slightly overestimates observed uplift magnitudes along the Irishman Creek fault zone. Although within error for the calculated slip rates, absolute elevations of terraces at the frontal scarp are undoubtedly affected by both erosion and extension at the top of the hanging wall [Erslev, 1986; Seeber and Sorlien, 2000] and nonrigid behavior of the actively subsiding footwall. The overall range of reported slip rates for terraces along Irishman Creek $(\sim 0.5-0.7 \mathrm{~mm} / \mathrm{yr})$ however, is consistent with previous estimates of vertical displacement rates of $\sim 0.6 \mathrm{~mm} / \mathrm{yr}$ [Fox, 1987; Barrell and Cox, 2003], thereby lending 
A.
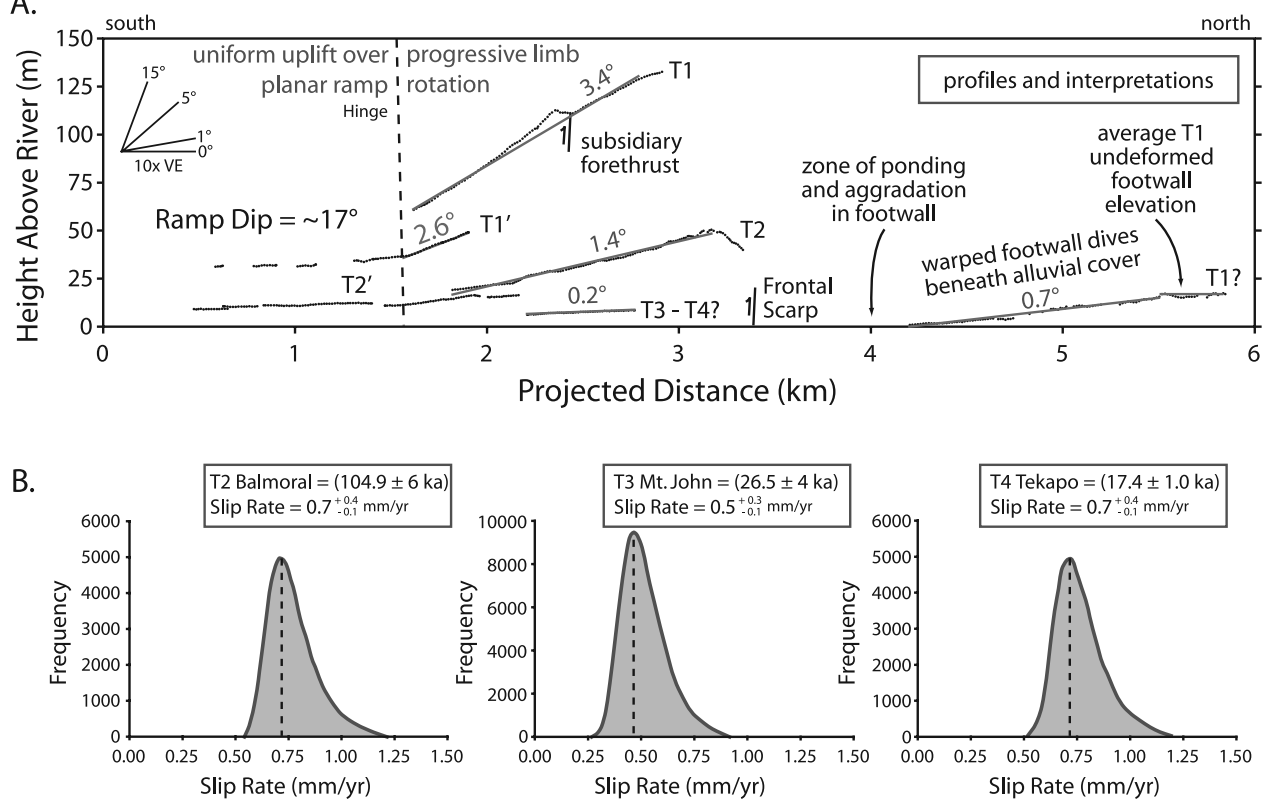

Figure 14. Irishman Creek terrace profiles and associated slip rates calculated from backlimb tilting. (a) Terrace profiles from topographic surveying and interpretations. Terrace elevations are corrected for height above the modern river and show broad, tilted backlimbs that roughly parallel the modern river downstream of the hinge or axial surface. Note the tilting of the T1 footwall surface as it dives beneath the alluvial cover caused by ponding and aggradation against the frontal scarp. (b) Histograms of calculated slip rate output from the Monte Carlo simulation for each terrace in Figure 14a. Estimated slip rates of $\sim 0.5-0.7 \mathrm{~mm} / \mathrm{yr}$ are internally consistent between multiple terrace levels.

support to the rigid rotation model as a valid approximation of folding over the Irishman Creek fault.

\section{Subsurface Fault Geometry}

[41] Given the overall compatibility of folded terraces along the Ohau River and the Irishman Creek water gap with predicted surface geometries for listric thrust-related folding (Figure 9c), accurate measurement of the topographic parameters associated with the listric thrust model (Figure 10) enables estimation of fault geometry in the subsurface (Appendix A). The results of geometric predictions from the Monte Carlo simulation for both the Ostler and Irishman Creek fault zones are presented in Table 2. For the Ohau terraces, using the Tekapo T4 surface to measure backlimb width and the hinge position for both Mount John T3 and Balmoral T2 terraces (Figure 13a) yields a dip of $12_{-4}^{+7} \mathrm{SW}$ for the planar ramp underlying flat terrace segments.

[42] The upper end of this estimate agrees well with the observed $\sim 10 \mathrm{~m}$ of differential uplift for the T3 surface using the calculated magnitude of slip ( 22-30 m) from backlimb tilting of the T3 and T4 terraces (Figure 12). Predicted values of the depth to the listric-to-planar transition and the ratio of depth to backlimb width using calculated ramp $\operatorname{dip}\left(\theta_{2}\right)$ and step-up angle $(\phi)$ values are estimated at $0.7_{-0.2}^{+0.1} \mathrm{~km}$ and $0.50 \pm 0.08$, respectively (Figure 15). For the Irishman Creek fault, measurement of backlimb width from the T1 Wolds surface combined with the hinge position for the $\mathrm{T}^{\prime}$ and $\mathrm{T} 2$ terraces suggests a ramp dip of $17_{-7}^{+24 \circ} \mathrm{SE}$. There, the ramp depth is predicted at $1.3_{-0.5}^{+0.1} \mathrm{~km}$ with a corresponding ratio to backlimb width of $0.50_{-0.21}^{+0.04}$ (Figure 15).

[43] Because of the lack of continuity of deformed surfaces across the Irishman Creek fault zone, differential uplift estimates from hanging wall to footwall are unavailable to independently evaluate predictions of ramp dip at depth. The observed magnitude of terrace incision along Irishman Creek should, however, reflect the combination of incision driven by uplift over the fault and that related to climatic fluctuation in the absence of significant aggradation

Table 2. Geometric Predictions Output From Monte Carlo Simulation

\begin{tabular}{lccc}
\hline & & \multicolumn{2}{c}{$95 \%$ Confidence Interval } \\
\cline { 3 - 4 } Parameter & Mode & Lower Bound & Upper Bound \\
\hline & Ostler & Fault Zone & $(\text { OFZ })^{\mathrm{a}}$ \\
Ramp dip $\theta_{2}$, deg & 12 & 8 & 19 \\
Step-up angle $\phi$, deg & 42 & 37 & 49 \\
Ramp depth d, km & 0.7 & 0.5 & 0.8 \\
Ramp depth/backlimb width & 0.50 & 0.42 & 0.58
\end{tabular}

$\begin{array}{lll}\text { Ramp depth/backlimb width } \quad 0.50 & 0.42 & 0.58\end{array}$

\begin{tabular}{|c|c|c|c|}
\hline \multicolumn{4}{|c|}{ Irishman Creek Fault Zone $(I C F Z)^{\mathrm{b}}$} \\
\hline Ramp dip $\theta_{2}, \operatorname{deg}$ & 17 & 10 & 41 \\
\hline Step-up angle $\phi$, deg & 36 & 24 & 40 \\
\hline Ramp depth d, km & 1.3 & 0.8 & 1.4 \\
\hline Ramp depth/backlimb width & 0.50 & 0.29 & 0.54 \\
\hline
\end{tabular}

${ }^{\mathrm{a}}$ Geometric calculations performed using a measured surface fault dip of $56 \pm 9^{\circ}$ from GPR and a measured backlimb width $(W)$ of $1.29 \mathrm{~km}$ from Tekapo reference surface.

${ }^{\mathrm{b}}$ Geometric calculations performed using an assumed surface fault dip of $55 \pm 20^{\circ}$ reported by E. M. Chetwin and T. A. Stern (manuscript in preparation, 2006) and a measured backlimb width $(W)$ of $2.63 \mathrm{~km}$ from Wolds reference surface. 


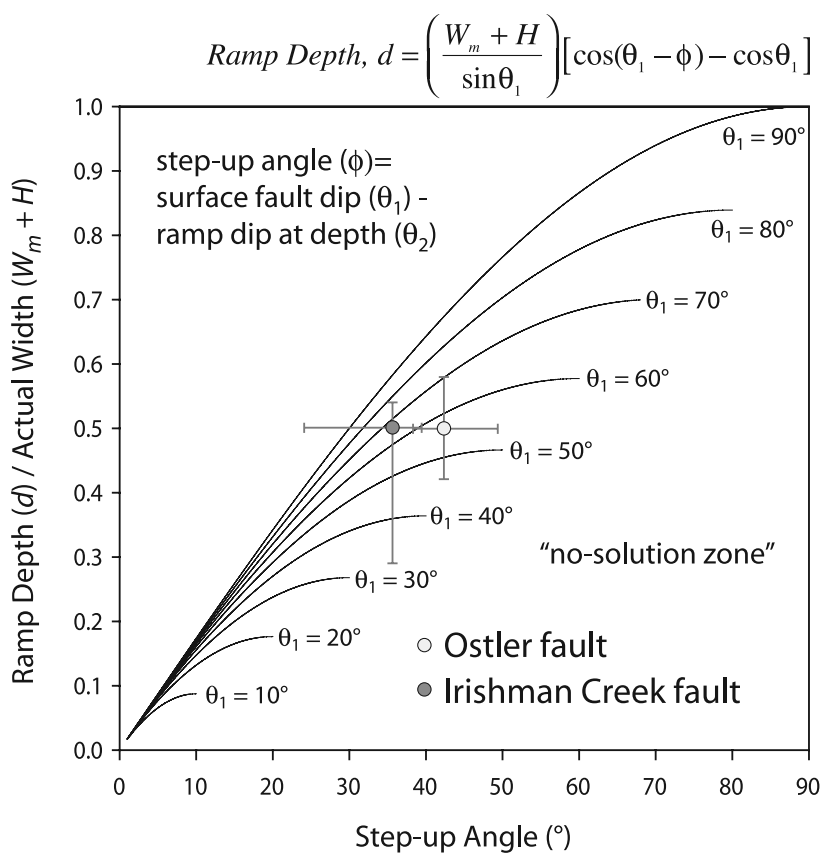

Figure 15. Depth of listric faulting. Predicted values of ramp depth $d$, for various values of surface fault dip and step-up angle, defined as the difference between surface fault dip and ramp dip at depth. Calculated values for the Ostler and Irishman Creek fault zones represent output from the Monte Carlo simulation and the associated 95\% confidence intervals.

or changes in sinuosity and gradient since terrace formation [Lavé and Avouac, 2000; Pazzaglia and Brandon, 2001]. If so, the $\sim 15 \mathrm{~m}$ height of the probable Wolds T1 terrace north of the fault zone reflects only the climatic signal provided that it is sufficiently removed from the area affected by footwall tilting. Comparison with the $\sim 40 \mathrm{~m}$ height of the Wolds T1 surface farther downstream suggests a total of $\sim 25 \mathrm{~m}$ of differential uplift of this terrace over the planar ramp at depth. As such, the predicted magnitude of slip from the listric thrust model $(\sim 190 \mathrm{~m})$ based on the $3.4^{\circ}$ tilt of this surface suggests a slightly gentler ramp dip than the calculated $17_{-7}^{+24 \circ}$, even at the $95 \%$ confidence level. This discrepancy is exacerbated through correlation of the footwall $\mathrm{T} 1$ terrace with the lower $\mathrm{T}^{\prime}$ remnant in the hanging wall. If indeed correlated, predicted slip values $(\sim 170 \mathrm{~m})$ would require a ramp no steeper than $\sim 5^{\circ}$ connecting to the listric fault segment. We therefore consider the $\mathrm{T} 1$ footwall surface to be correlative with the higher T1 hanging wall terrace and use the predicted $17^{\circ}$ as a maximum bound on ramp dip at depth. Given the overall sensitivity of predictions from the listric thrust model to fault dip at the surface, reported overestimation of ramp dip for the Irishman Creek fault most likely reflects poor estimates of fault dip in the absence of shallow subsurface constraints from GPR.

[44] In their study of fault linkage and segment interaction along the Ostler fault zone, Davis et al. [2005] suggested that much of the observed segmentation for fault scarps at the surface reflects rupturing through Cenozoic stratigraphy preserved throughout the Mackenzie Basin. Because of strong mechanical contrasts between the Tor- lesse graywacke and the overlying Cenozoic basin fill, they infer that basin depth exerts first-order control on the degree of segmentation at the surface of single, discrete fault planes rooted in basement. Here we note an apparently similar influence of Late Quaternary outwash thickness on the style of surface folding. Where the Ruataniwha segment of the Ostler fault crosses a major outwash channel inset into a Mount John T3 surface (Figure 3), hanging wall folding changes from relatively planar back tilting to broader anticlinal warping. Back tilting occurs with both associated normal faulting at the fold crest and a single scarp at the toe of the fold, whereas distributed folding is accompanied by less abrupt fold forelimbs and a suite of frontal fault scarps. Although untested by our analysis, we suspect that the observed along-strike variation in fold style reflects the ability of relatively unconsolidated outwash deposits to distribute or absorb deformation associated with extension at the top of the backlimb as predicted by the listric thrust model (Figure 10). Apparently thinner outwash to the south results in hanging wall collapse of more lithified Tertiary bedrock and development of a crestal graben system to accommodate localized extension at the backlimb crest. Along the Irishman Creek fault zone, however, abrupt forelimbs developed in Kurow group conglomerates (Figure 7) show no evidence of extensional collapse, suggesting a range in mechanical response for the Tertiary bedrock. Additionally, along-strike variations in surface folding style could instead reflect lateral changes in fault geometry or radius of curvature (see discussion below).

[45] Additional indication that basin architecture may influence the pattern of active thrusting in the Mackenzie Basin comes from rough correspondence between the depth of Cenozoic deposits and the calculated transition depth from planar to listric faulting. On the basis of seismic and gravity data across the Irishman Creek fault, E. M. Chetwin and T. A. Stern (manuscript in preparation, 2006) estimate a depth of Tertiary basin fill of $1.6 \pm 0.3 \mathrm{~km}$ based on a prominent reflector at the base of the Tertiary sequence. This result stands in general agreement with the predicted $1.3_{-0.5}^{+0.1} \mathrm{~km}$ depth to the top of the planar ramp beneath the Irishman Creek fault hanging wall from the geometric analysis of deformed terrace surfaces presented here. E. M. Chetwin and T. A. Stern (manuscript in preparation, 2006) also estimate a dip for this basal reflector of $14 \pm 3^{\circ}$ and suggest an increase in dip toward the fault. Constraints on the calculated dip of the lower ramp $\left(<17^{\circ}\right)$ from the listric thrust model indicate that deeper portions of the Irishman Creek fault may be rooted along this dipping interface at the base of the Tertiary section. Although lacking detailed seismic constraints, an estimated depth of Cenozoic basin fill of approximately $0.75 \mathrm{~km}$ from gravity surveying along the Ruataniwha segment of the Ostler fault zone (S. Kleffmann and T. A. Stern, manuscript in preparation, 2006) also overlaps with the predicted $0.7_{-0.2}^{+0.1} \mathrm{~km}$ ramp depth from our analysis of the Ohau River terraces.

[46] On the basis of apparently thicker Cenozoic fill corresponding to a pronounced negative gravity anomaly in the hanging wall of the Ruataniwha fault (S. Kleffmann and T. A. Stern, manuscript in preparation, 2006), Ghisetti [2005] suggests that the active geometry of the Ostler fault reflects reactivation of a normal fault bounding a marine basin of latest Mesozoic through Tertiary age buried 


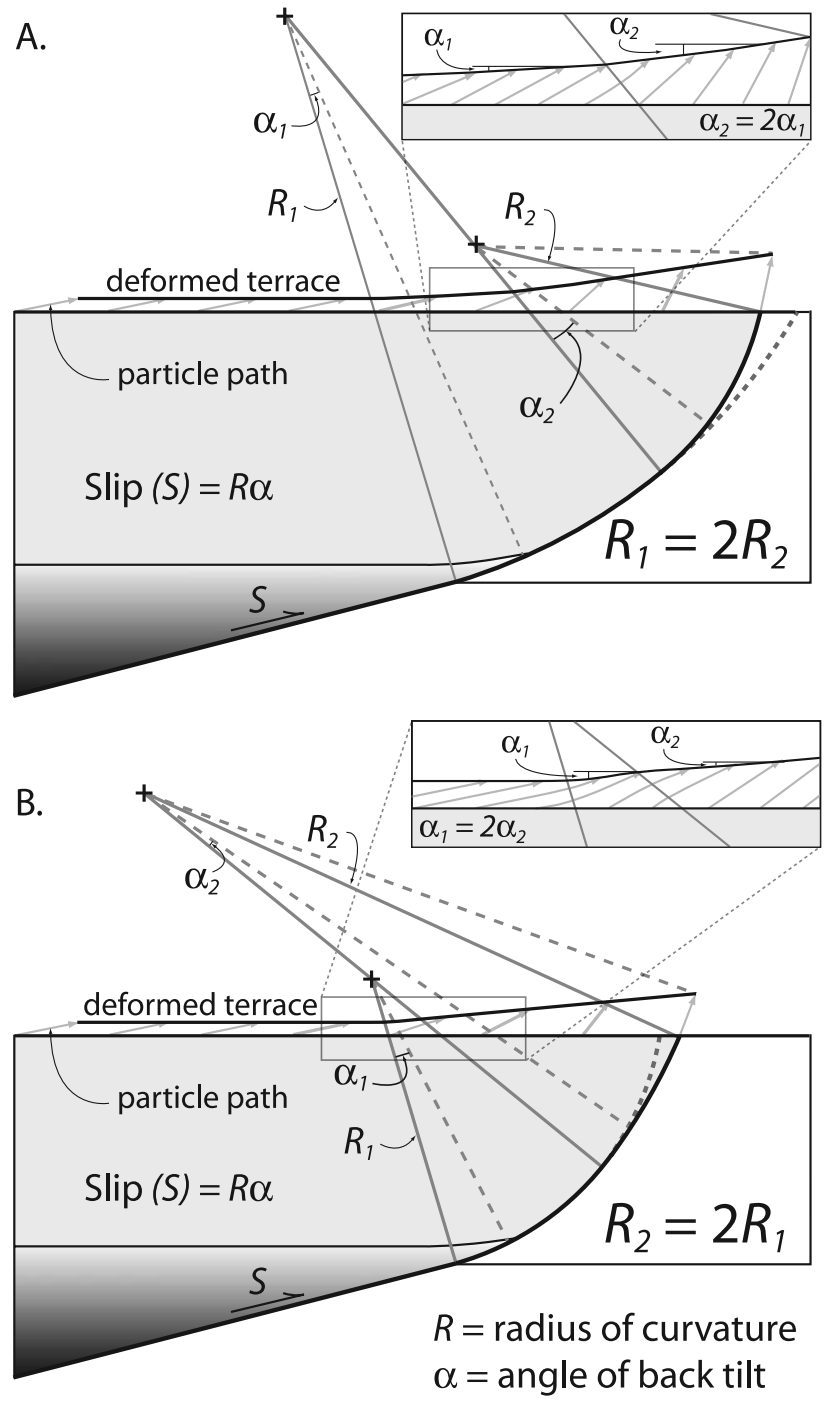

Figure 16. Schematic illustration of the effects of variations in fault curvature. (a) Halving the radius of curvature midway along a listric fault results in a doubling of backlimb tilting and concavity of the folded backlimb. (b) Doubling the radius of curvature along the fault arc may produce a slight backlimb convexity at lower step up angles and surface fault dips. Insets are enlargements of surface deformation associated with changes in fault curvature. Using a single linear regression to the folded backlimb in both cases may exaggerate calculated slip rates by $<15 \%$ for the factor of 2 changes in fault curvature depicted here.

beneath Plio-Pleistocene deposits. Although consistent with listric reactivation of former extensional faults in New Zealand [Litchfield, 2001] and elsewhere [McClay et al., 2004], the relatively shallow depth of listric faulting indicated by our results suggests confinement of curved fault segments largely within the postextensional stratigraphy. Additionally, gentle dips of each fault in the deeper subsurface $\left(<20^{\circ}\right)$ and the potential for the Irishman Creek fault zone to root along the basement interface are difficult to reconcile with the relatively shallow nature of these structures if they are indeed reactivated normal faults. Whereas the methods presented here provide a general approximation of fault geometry at depth, additional subsurface information is required to further evaluate active deformation in the Mackenzie Basin as reflecting fault inversion.

\section{Discussion}

[47] The validity of geometric predictions output from the listric thrust model presented here strongly depends on its applicability in approximating fault shape and predicting the kinematics of terrace deformation with progressive slip. Although appealing in its relative simplicity and ability to convert readily observable surface data to fault slip and geometry, we recognize the likelihood that listric fault geometries are not perfectly circular with depth in a natural system. As such, we consider the effects of changing fault curvature along a listric fault segment on surficial deformation patterns and subsequent geometric predictions (Figure 16). For the case of halving the radius of curvature along the fault arc (Figure 16a), continuity in slip along the ramp requires the rotation angle to double in response to the shortened rotational radius. Accordingly, surface tilting within this domain also doubles, resulting in a concave fold backlimb comprising two quasi-linear segments. Such a case may exist for the Ostler fault zone, where concave portions the higher $\mathrm{T} 2 \mathrm{~N}$ terrace deviate from the linear regression through this surface (Figure 13a). Such concavities, however, are absent from lower terrace levels along the Ohau River and may reflect along-strike changes in fault curvature.

[48] In contrast, doubling of the radius of curvature midway along the listric fault segment requires the rotation angle and associated backlimb tilting to be reduced by half (Figure 16b). This geometry results in a slight convexity along the folded backlimb, although the magnitude of this inflection at the surface is reduced at greater step-up angles and may be difficult to detect in survey measurements. In either case, applying a single linear regression through the fold backlimb may overestimate calculated slip rates by averaging out angular changes associated with curvature variations and consequently affecting the measured backlimb width. Through simple consideration of the arithmetic mean of the radii and rotation angles depicted in Figure 16, artificial inflation of calculated slip rates is limited to $<15 \%$ for factor of two changes in the radius of curvature. Although not restricted to these specific cases, such changes in fault curvature are likely to introduce uncertainty that is unaccounted for in the model calculations. In spite of this effect, general agreement between calculated slip rates and previously published estimates highlights the utility of our model in approximating fault geometry from surface observations alone.

[49] Hanging wall deformation that is required across changes in fault curvature [Erslev, 1986] can be manifested as either subsidiary faulting or flexural slip along bedding planes. Such deformation may also introduce a significant and unknown degree of uncertainty in the model predictions [Bulnes and McClay, 1999; Yamada and McClay, 2003]. The presence of synthetic and antithetic thrust scarps running roughly parallel to the main fault traces indicates that active compressional deformation is ongoing in the hanging walls of both the Ostler and Irishman Creek fault zones (Figures 3 and 6). These scarps match kinematic 
predictions emerging from the listric thrust model that require hanging wall internal deformation and may represent flexural slip faults that accommodate layer-parallel shear along bedding planes within the tilted Tertiary strata. We emphasize again that such faulting can occur without violating the geometric relationships prescribed by the rigid rotation model [Seeber and Sorlien, 2000], especially given the relatively small magnitude of slip associated with terrace deformation. Even for the older, Wolds T1 terrace along the Irishman Creek fault zone (Figure 8), the observed $\sim 10 \mathrm{~m}$ of displacement represents only $\sim 5 \%$ of the $\sim 200 \mathrm{~m}$ of slip implied by the $3.4^{\circ}$ tilt of this surface. Thus, while important in accommodating internal deformation as the hanging wall adjusts to fault curvature, such displacements are relatively insignificant and are likely to detract little from the accuracy of our geometric predictions.

[50] Other potential sources of uncertainty in our analysis may result from errant correlation or age assignment for undated terrace remnants, projection of survey data oblique to the active axial surfaces, changes in the river long profile or sinuosity in the past [Lavé and Avouac, 2000; Pazzaglia and Brandon, 2001], and elastic storage of slip either currently or during periods of strath beveling [Lavé and Avouac, 2000; Thompson et al., 2002].

\section{Conclusion}

[51] Deformed terrace geometries preserved over the Ostler and Irishman Creek faults are incompatible with fault bend [Suppe, 1983], fault propagation [Suppe and Medwedeff, 1990], and trishear [Erslev, 1991] models for thrust-related folding. Except in the case of high-magnitude flexural slip, differential uplift rates over planar fault ramps associated with these models display a general spatial uniformity [Hardy and Poblet, 2005], and none can account for the geometry of apparent limb rotation implied by progressive tilting across these structures. Other models for limb rotation such as detachment folding [e.g., Hardy and Poblet, 1994; Scharer et al., 2006] and shear fault bend folding [Suppe et al., 2004] are also inconsistent with surface deformation patterns along the Ostler and Irishman Creek fault zones, where folds characterized by broadly smooth and continuous backlimbs and abrupt forelimbs that lack kinks, show progressive limb rotation in the hanging wall of an emergent thrust. We demonstrate that this pattern of folding is diagnostic of deformation over a curved, or listric thrust fault at depth.

[52] In addition to highlighting the use of fluvial terraces in unraveling the kinematics of fault-related fold growth in the absence of seismic control, our analysis supports the following conclusions about the nature of active thrusting in the Mackenzie Basin:

[53] 1. The Ostler and Irishman Creek faults are active listric thrusts faults that pass from gently dipping $\left(<20^{\circ}\right)$ planar faults in the deeper subsurface to curved ramps that increase in dip to values greater than $50^{\circ}$ where they rupture the surface. On the basis of observed magnitudes of differential uplift over each fault zone, ramp dip at depth for the Irishman Creek fault is expected to be gentler $\left(<10^{\circ}\right)$ than the predicted $17^{\circ}$ based on geometric constraints from the listric thrust model.
[54] 2. Measured fault dips for shallow segments of the Ostler fault zone from GPR over active scarps along the Ruataniwha segment show a mean value of $56 \pm 9^{\circ}(2 \sigma)$, in general agreement with estimates based on offset of successive terrace levels $\left(50 \pm 9^{\circ}(1 \sigma)\right)$ [Davis et al., 2005].

[55] 3. Both synthetic and antithetic thrusts accommodate compressional internal deformation of the hanging wall along the Ostler and Irishman Creek fault zones. Extension at the top of the fold backlimb (Figure 4) is accommodated either through hanging wall collapse and associated crestal graben development or through distributed faulting and folding where outwash gravels are sufficiently thick.

[56] 4. The preferred range of calculated slip rates based on the degree of backlimb tilt for the Ostler fault zone $(\sim 1.1-1.7 \mathrm{~mm} / \mathrm{yr})$ and the Irishman Creek fault zone $(\sim 0.5-0.7 \mathrm{~mm} / \mathrm{yr})$ are generally internally consistent between multiple terrace levels and are compatible with previously published differential uplift rate estimates.

[57] 5. Predicted transition depths from listric to planar faulting for the Ostler and Irishman Creek faults of $0.7_{-0.2}^{+0.1} \mathrm{~km}$ and $1.3_{-0.5}^{+0.1} \mathrm{~km}$, respectively, match geophysical predictions of the depth of basin fill overlying graywacke basement (E. M. Chetwin and T. A. Stern, manuscript in preparation, 2006; S. Kleffmann and T. A. Stern, manuscript in preparation, 2006) and indicate some degree of basement control on active thrust geometry. Along the Irishman Creek fault, seismic evidence for a gently dipping $\left(14^{\circ}\right)$ reflector at this depth (E. M. Chetwin and T. A. Stern, manuscript in preparation, 2006) suggests rooting of the listric segment to a planar ramp along the basement interface.

\section{Appendix A: Slip Rate Measurement and Fault Geometry Prediction}

[58] Rigid rotation of an originally horizontal terrace by an angle, $\alpha$, over a listric thrust fault with a surface width $W_{a}$ and a shallow fault $\operatorname{dip}, \theta_{1}$, results in an equal magnitude of backlimb tilting (Figure A1). Measurement of backlimb width, however, requires projection back to the undeformed footwall elevation as an independent datum (Figure A2), because the height of a deformed terrace tread above the present river channel reflects both structural uplift and climatically driven incision [e.g., Lavé and Avouac, 2000; Pazzaglia and Brandon, 2001]. As illustrated for a Tekapo age surface along the Ostler fault (Figure A2), extrapolation of a least squares linear regression through the planar segment of the back tilted hanging wall to the average elevation of the footwall tread yields a measure of width and the associated uncertainty at the $95 \%$ confidence level.

[59] The measured value of backlimb width at the surface is also reduced by the tendency for material lines to project closer to the fault front with increasing magnitudes of rigid rotation (Figure A3). We term this reduction "hinge migration," $(H)$, which depends on the measured width of the tilted backlimb $\left(W_{m}\right)$ and the fault dip in the shallow subsurface $\left(\theta_{1}\right)$. For the simple case of no vertical elevation changes of the horizontal datum presented in Figure A3, the magnitude of hinge migration is given by

$$
H=y^{\prime} \sin \alpha-r,
$$




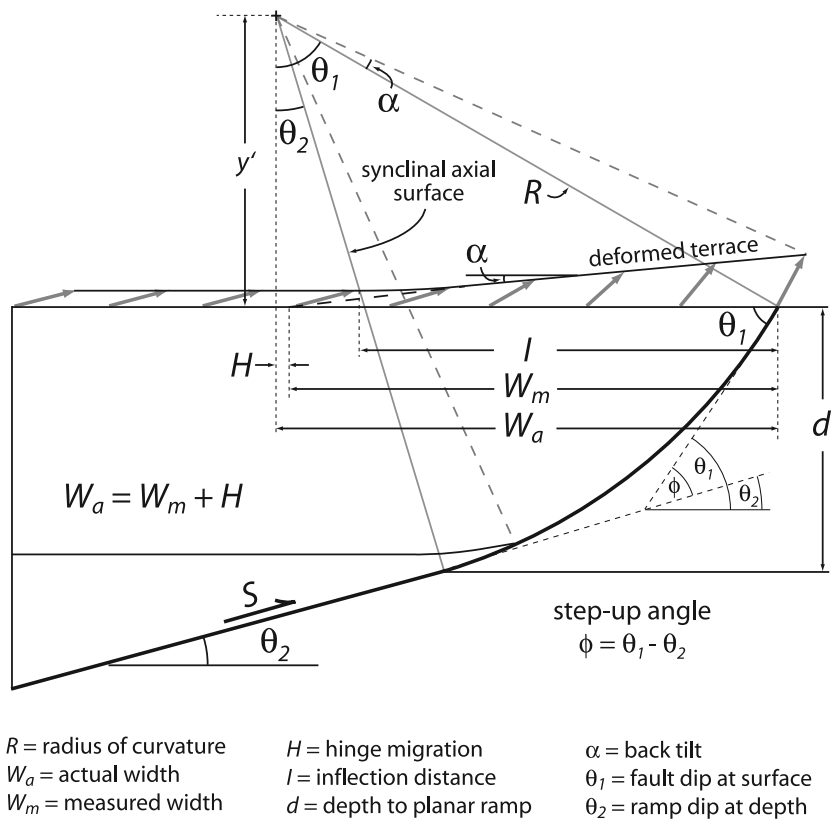

Figure A1. Geometric elements used in calculating fault slip, ramp dip, and depth of listric faulting from deformed terrace surfaces over a listric thrust fault.

where

$$
y^{\prime}=\frac{W_{a}}{\tan \theta_{1}},
$$

and

$$
r=\frac{y^{\prime}-y^{\prime} \cos \alpha}{\tan \alpha} .
$$

Substitution of equations (A2) and (A3) into (A1) yields

$$
H=\left(\frac{W_{a}}{\tan \theta_{1}}\right) C,
$$

where

$$
C=\sin \alpha-\left(\frac{1-\cos \alpha}{\tan \alpha}\right)
$$

is constant at a given magnitude of rotation, $\alpha$. Inserting the relationship $W_{m}=W_{a}+H$ into (A4) and rearranging to solve for $H$ then yields

$$
H=\frac{W_{m}}{\left[\left(\frac{\tan \theta_{1}}{C}\right)-1\right]}
$$

as a description of the magnitude of hinge migration with progressive fault slip. The effects of hinge migration, although typically small, can lead to underestimation of backlimb width by up to $10 \%$ for tilts less than $10^{\circ}$ with surface fault dips steeper than $40^{\circ}$ (Figure A4).

[60] Because slip along a listric thrust can be described by rotation along a circular arc, the amount of slip, $S$, necessary to produce a tilt of magnitude, $\alpha$, is given by the relationship $R \alpha$ [Erslev, 1986; Seeber and Sorlien, 2000] (Figure A1). $R$ is the radius of curvature of the listric fault segment and can be measured as

$$
R=\frac{W_{a}}{\sin \theta_{1}},
$$

provided that the subsurface fault geometry can be approximated as the arc of a circle. Substituting $W_{m}+H$ for $W_{a}$ in equation (A7) and multiplying by $\alpha$ yields a measure of fault slip determined from the observed magnitude of backlimb tilting:

$$
S=\frac{\left(W_{m}+H\right) \alpha}{\sin \theta_{1}} .
$$

Fault slip rates are then calculated by dividing the total slip by the surface age.

[61] For the case of a listric thrust rooted at depth into a planar fault ramp, deformed terrace surfaces transition from flat terrace treads to progressively tilted backlimbs across

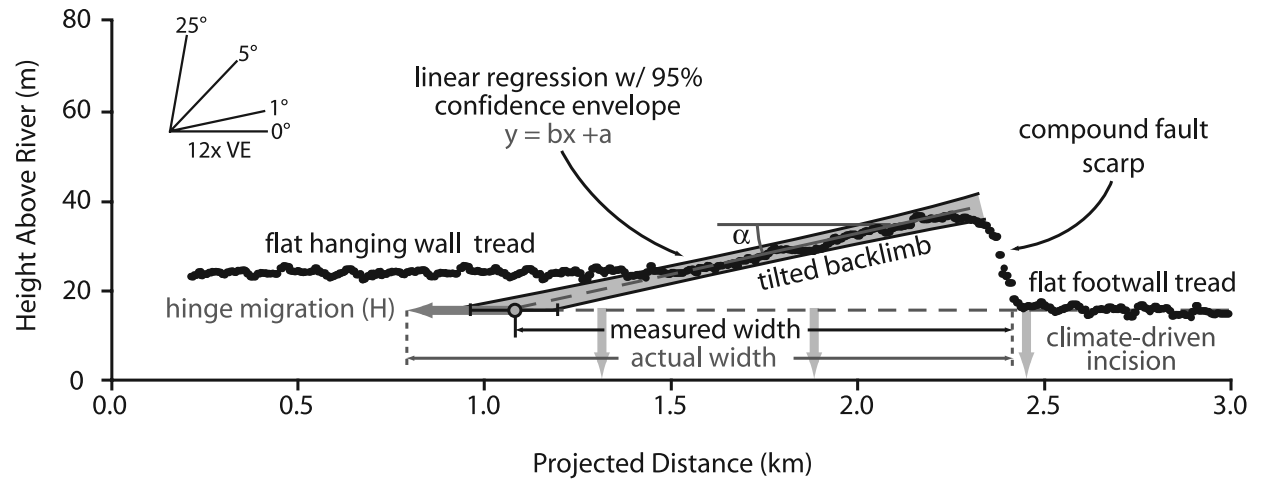

Figure A2. Backlimb width measurement. Extrapolation of a linear regression through the planar backlimb to the mean elevation of the undeformed footwall yields a measured value of backlimb width. Uncertainties associated with this measurement reflect errors in the survey measurements as well as the effects of hinge migration. The vertical difference between flat segments of the hanging wall tread and the mean footwall elevation gives the differential uplift over the planar ramp at depth, while the absolute elevation above the modern river reflects both uplift and climatically driven incision. 


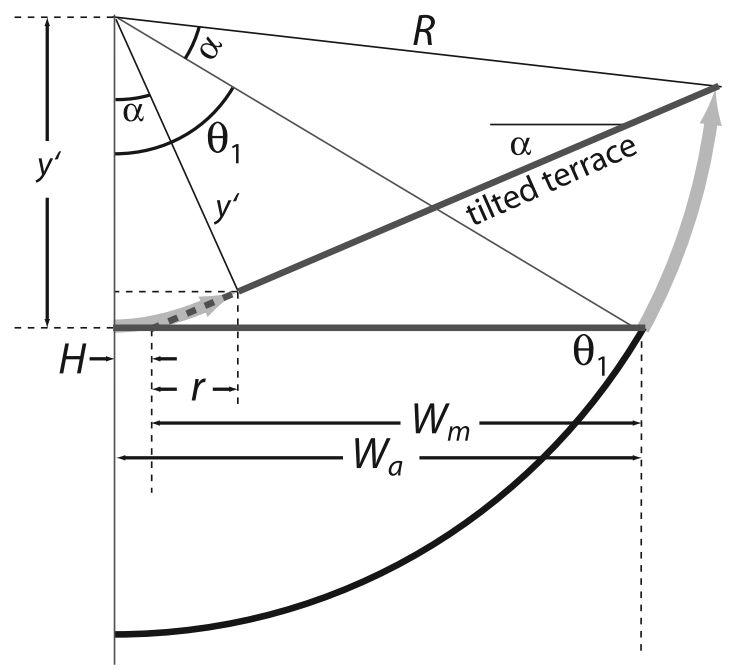

$R=$ radius of curvature

$W_{a}=$ actual width

$W_{m}=$ measured width

$H=$ hinge migration

$\alpha=$ angle of back tilt

$\theta_{1}=$ fault dip at surface

Figure A3. Geometric elements used in calculating the magnitude of hinge migration, $H$, associated with progressive rotation of an originally horizontal terrace surface. For a given magnitude of rigid rotation, $\alpha$, over a listric fault, the projection of a tilted terrace back to the horizontal will be offset from the hinge or synclinal axial surface by an amount, $H$, termed here as hinge migration.

the active synclinal axial surface (Figure A1). Comparison of measured values of backlimb width with the inflection point marking this transition allows estimation of ramp dip at depth $\left(\theta_{2}\right)$. Assuming that the synclinal axial surface is perpendicular to the planar fault ramp at depth, ramp dip is given by:

$$
\theta_{2}=\arctan \left(\frac{W_{a}-I}{y^{\prime}}\right)
$$

where $I$ is the measured distance between the frontal fault scarp and the planar to tilted inflection position of the deformed terrace. Substitution of equation (A2) for $y^{\prime}$ and $W_{m}+H$ for $W_{a}$ into equation (A9) then yields

$$
\theta_{2}=\arctan \left[\left(1-\frac{I}{\left(W_{m}+H\right)}\right) \tan \theta_{1}\right]
$$

as a measure of ramp dip in the deeper subsurface. As a check on the validity of this prediction, the observed value of differential uplift across the fault for untilted terrace segments should be compatible with the sine of the predicted ramp dip, $\theta_{2}$ times the magnitude of slip from equation (A8) calculated from backlimb tilting (Figure 10).

[62] This predicted value of ramp dip can then be used to calculate the depth, $d$, to the top of the planar ramp. The angular difference between the dip of the planar fault at depth, $\theta_{2}$, and the shallow subsurface fault dip, $\theta_{1}$, defines the "step-up angle," $\phi$ (Figure A1). Through geometric consideration of this angle and the measured backlimb width, the depth to the top of the planar ramp $(d)$ is then given by

$$
d=R\left(\cos \theta_{2}-\cos \theta_{1}\right) .
$$

Because $\theta_{2}$ is equal to $\theta_{1}$ minus the step-up angle, $\phi$, using equation (A7) to cast $R$ in terms of backlimb width and substituting $\left(W_{m}+H\right)$ for $W_{a}$ yields

$$
d=\left(\frac{W_{m}+H}{\sin \theta_{1}}\right)\left[\cos \left(\theta_{1}-\phi\right)-\cos \theta_{1}\right]
$$

as an estimate of the depth of listric faulting from deformed surface geometries. Values of the step-up angle cannot exceed the surface fault dip and thus define a

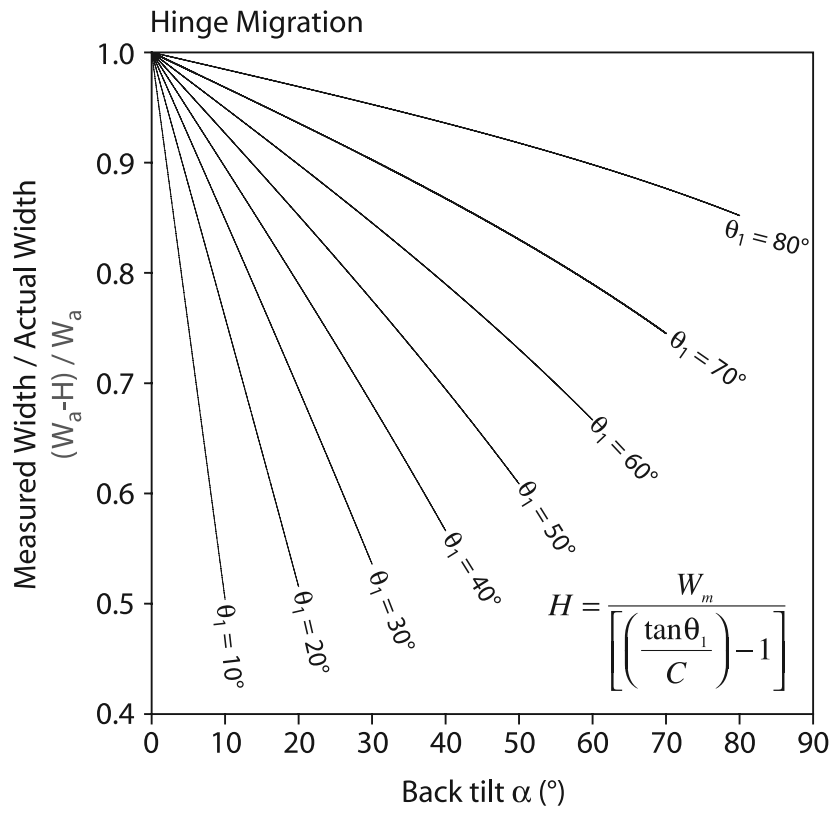

Figure A4. Hinge migration. The magnitude of hinge migration depends on the surface fault dip, $\theta_{1}$, the measured width of the tilted backlimb, $W_{m}$, and the degree of backlimb tilting, where $C$ is a constant given by equation (A5). Normalizing the measured backlimb width by the actual width, $W_{a}$, illustrates the effects of hinge migration with increasing tilt and rotation for various values of surface fault dip. 
"no-solution zone" of possible ramp depths for each value of $\theta_{1}$ (Figure 15).

\section{Appendix B: Ground-Penetrating Radar Data Acquisition and Processing}

[63] We used a Sensors \& Software pulseEKKO 100A ground-penetrating radar (GPR) system, with $50 \mathrm{MHz}$ bistatic antennas. Two types of surveys were carried out: Common offset profiles were gathered with the antennas at a fixed 2-m separation and towed upslope along each survey line in turn. The antennas were then stepped out parallel to the strike of the scarp from a common midpoint (CMP) either at the start or end of the survey lines.

[64] The common offset profiles were acquired in "continuous" mode, that is the antennas were towed at a slow and approximately constant speed. The survey area was $20 \mathrm{~m}$ wide by $50 \mathrm{~m}$ long, centered on the thrust scarp. 21 survey lines in total were acquired, with a line spacing of $1 \mathrm{~m}$. As certain markers were passed, flags were placed on the records. Reference markers for known positions were placed at the starts and ends of the lines and at base and top of the scarp slope. The starts of the lines were $15 \mathrm{~m}$ from base of slope. The average raw trace spacing was $26 \pm 8 \mathrm{~cm}(2 \sigma)$. The data were later "rubberbanded", i.e., the trace spacing is interpolated to yield a constant distance between successive traces on one profile, in this case $30 \mathrm{~cm}$. The processed profiles were then migrated using the velocities derived from the CMP profiles. Migration collapses diffractions due to truncated beds and large, discrete objects to points and places dipping beds into their correct steeper and deeper orientations [cf. Yilmaz, 2001]. Finally, the topography of the survey lines was obtained using differential GPS surveying, which also allowed us to check the GPR profile distances originally laid out using tape measures. Cumulative errors in positioning were less than $20 \mathrm{~cm}$ and generally of the order of $10 \mathrm{~cm}$ over the $50 \mathrm{~m}$ lengths of the survey lines.

[65] The CMP profiles were acquired by stepping the antennas out $20 \mathrm{~cm}$ at a time from a central point, starting with $1.2-\mathrm{m}$ antenna separation and increasing to $32-36 \mathrm{~m}$, depending on the conditions and retention of subsurface echoes. The net increase in transmitter-receiver separation was thus $40 \mathrm{~cm}$ with each trace. The CMP profiles are then analyzed using semblance analysis [Hatton et al., 1986; Yilmaz, 2001], which yielded velocities of $110-120 \mathrm{~m} / \mu \mathrm{s} \pm$ $5-10 \mathrm{~m} / \mu \mathrm{s}$, consistent with the relatively unsaturated sands and gravels we know to be present.

[66] Additional data processing included semblance (velocity) analysis for the CMP profiles and migration and topography for the stepped profiles. The GPR echo two-way traveltime (TWT) is at least $200-240 \mathrm{~ns}$, which is of the order of $12-15 \mathrm{~m}$ depth of penetration, given the velocities obtained from the CMP profiles. We use the velocities to convert TWT to depth. We can also use the velocities to estimate the lateral resolution, which is 55 to $60 \mathrm{~cm}$ or one quarter of the wavelength in the ground [e.g., Jol and Bristow, 2003]. Thus the data were oversampled across the fault and slightly undersampled along the strike of the fault. Vertical resolution is typically one half to one third of the lateral resolution.

[67] The closely spaced profiles were then combined into three-dimensional data cubes. This allows us to look only at those features that have continuity across the survey area. The data cubes can also be "sliced" at constant times and compared with individual profiles. By going back and forth between cutout data cubes and the processed profiles, we can determine the presence and locations of individual buried fault traces. We can also determine the fault dips, because we have converted TWT to depths. The accuracy of the depth conversion is 4.5 to $9 \%$, a small error when estimating dips. From the GPR profiles acquired across the Ostler fault zone, we obtain dips of $56 \pm 9^{\circ}$, where the $2 \sigma$ error represents the scatter in the measured dips $(n=14)$.

[68] Acknowledgments. We are indebted to the many farmers and landowners in the Mackenzie Basin for making this work possible by granting us unrestricted access to their lands. We also thank Julie Fosdick and Brian Clarke for help in the field, Bodo Bookhagen and Nathan Niemi for technical assistance, and the residents of Twizel, New Zealand, for their continued hospitality. Tim Stern kindly provided access to unpublished geophysical data. Hearty thanks go to Haikai Tane at the Centre for Catchment Ecology in Twizel for providing digital elevation data and high-resolution aerial photography. For logistical support, we thank Cathy Higgins and Joyce Seale at the University of Canterbury and the people at the Twizel Promotion and Development Agency. Uwe Rieser at the Luminescence Dating Laboratory, School of Earth Sciences, Victoria University, provided quick turnaround of OSL samples. Insightful reviews by Jean-Philippe Avouac, Kelvin Berryman, and Richard Norris significantly improved the manuscript. This research was supported by National Science Foundation grant EAR-0117242 and ACS Petroleum Research Fund grant 41960-AC8.

\section{References}

Abdrakhmatov, K. E., R. Weldon, S. Thompson, D. Burbank, C. Rubin M. Miller, and P. Molnar (2001), Origin, direction, and rate of modern compression of the central Tien Shan (Kyrgyzstan), Geol. Geofiz., 42(10), $1585-1609$

Aitken, M. J. (1998), An Introduction to Optical Dating: The Dating of Quaternary Sediments by the Use of Photon-Stimulated Luminescence, 267 pp., Oxford Univ. Press, New York.

Barnes, P. M., A. Nicol, and T. Harrison (2002), Late Cenozoic evolution and earthquake potential of an active listric thrust complex above the Hikurangi subduction zone, New Zealand, Geol. Soc. Am. Bull., 114(11), 1379-1405.

Barrell, D., and S. C. Cox (2003), Southern Alps tectonics and Quaternary geology, in Geological Society of New Zealand 2003 Annual Conference Field Trip Guide, edited by S. C. Cox and B. S. Lyttle, pp. 1-39, Geol. Soc. of N. Z., Wellington.

Benedetti, L., P. Tapponnier, G. C. P. King, B. Meyer, and I. Manighetti (2000), Growth folding and active thrusting in the Montello region, Veneto, northern Italy, J. Geophys. Res., 105(B1), 739-766.

Blick, G. H., S. A. L. Read, and P. T. Hall (1989), Deformation monitoring of the Ostler fault zone, South Island, New Zealand, Tectonophysics, 167, 329-339.

Boyer, S. E., and D. Elliot (1982), Thrust systems, AAPG Bull, 66(9), $1196-1230$.

Bull, W. B. (1990), Stream-terrace genesis: Implications for soil development, Geomorphology, 3, 351-367.

Bullard, T. F., and W. R. Lettis (1993), Quaternary fold deformation associated with blind thrust faulting, Los Angeles Basin, California, J. Geophys. Res., 98(B5), 8349-8369.

Bulnes, M., and K. McClay (1999), Benefits and limitations of different 2D algorithms used in cross-section restoration of inverted extensional faults: Application to physical experiments, Tectonophysics, 312, 175-189.

Campbell, J. K., A. Nicol, and M. E. Howard (2003), Long-term changes to river regimes prior to late Holocene coseismic faulting, Canterbury, New Zealand, J. Geodyn., 36(1-2), 147-168.

Cristallini, E. O., and R. W. Allmendinger (2002), Backlimb trishear: A kinematic model for curved folds developed over angular fault bends, J. Struct. Geol., 24(2), 289-295.

Davis, K., D. W. Burbank, D. Fisher, S. Wallace, and D. Nobes (2005), Thrust-fault growth and segment linkage in the active Ostler fault zone, New Zealand, J. Struct. Geol., 27(8), 1528-1546.

DeMets, C., R. G. Gordon, D. F. Argus, and S. Stein (1994), Effect of recent revisions to the geomagnetic reversal time-scale on estimates of current plate motions, Geophys. Res. Lett., 21(20), 2191-2194.

Duller, G. A. T. (1996), Recent developments in luminescence dating of Quaternary sediments, Prog. Phys. Geog., 20(2), 127-145. 
Erslev, E. A. (1986), Basement balancing of Rocky-Mountain foreland uplifts, Geology, 14(3), 259-262.

Erslev, E. A. (1991), Trishear fault propagation folding, Geology, 19(6), $617-620$.

Erslev, E. A., and J. L. Rogers (1993), Basement-cover geometry of Laramide fault-propagation folds, Spec. Pap. Geol. Soc. Am., 280, 125-146.

Formento-Trigilio, M. L., D. W. Burbank, A. Nicol, J. Shulmeister, and U. Rieser (2003), River response to an active fold-and-thrust belt in a convergent margin setting, North Island, New Zealand, Geomorphology, $49(1-2), 125-152$.

Fox, A. N. (1987), The neotectonic history of the Lake Tekapo region, Mackenzie Basin, New Zealand, M.Sc. thesis, Univ. of Canterbury, Christchurch, New Zealand.

Gair, H. S. (1967), Geological map of New Zealand, sheet 20, Mt. Cook, N. Z. Dep. of Sci. and Ind. Res., Wellington.

Ghisetti, F. C. (2005) The surface image of an actively growing - inverted? reverse fault: The Ostler fault in the Mackenzie basin (South Island, New Zealand), paper presented at 50th Annual Conference, Geol. Soc. of N. Z., Kaikoura, New Zealand.

Gold, R. D., E. Cowgill, X. F. Wang, and X. H. Chen (2006), Application of trishear fault-propagation folding to active reverse faults: Examples from the Dalong Fault, Gansu Province, NW China, J. Struct. Geol., 28(2), $200-219$.

Hancock, G. S., and R. S. Anderson (2002), Numerical modeling of fluvial strath-terrace formation in response to oscillating climate, Geol. Soc. Am. Bull., 114(9), 1131-1142.

Hardy, S., and J. Poblet (1994), Geometric and numerical model of progressive limb rotation in detachment folds, Geology, 22(4), 371-374.

Hardy, S., and J. Poblet (2005), A method for relating fault geometry, slip rate and uplift data above fault-propagation folds, Basin Res., 17(3), $417-424$

Hatton, L., M. H. Worthington, and J. Makin (1986), Seismic Data Processing: Theory and Practice, 177 pp., Blackwell Sci., Malden, Mass.

Ishiyama, T., K. Mueller, M. Togo, A. Okada, and K. Takemura (2004), Geomorphology, kinematic history, and earthquake behavior of the active Kuwana wedge thrust anticline, central Japan, J. Geophys. Res., 109 B12408, doi:10.1029/2003JB002547.

Jol, H. M., and C. S. Bristow (2003), GPR in sediments: Advice on data collection, basic processing and interpretation, a good practice guide, in Ground Penetrating Radar in Sediments, edited by C. S. Bristow and H. M. Jol, Geol. Soc. Spec. Publ., 211, 9-27.

Keller, E. A., D. B. Seaver, D. L. Laduzinsky, D. L. Johnson, and T. L. Ku (2000), Tectonic geomorphology of active folding over buried reverse faults: San Emigdio Mountain front, southern San Joaquin Valley, California, Geol. Soc. Am. Bull., 112(1), 86-97.

King, G. C. P., and C. Vita-Finzi (1981), Active folding in the Algerian earthquake of 10 October 1980, Nature, 292(5818), 22-26.

Lavé, J., and J. P. Avouac (2000), Active folding of fluvial terraces across the Siwaliks Hills, Himalayas of central Nepal, J. Geophys. Res., 105(B3), 5735-5770

Litchfield, N. J. (2001), The Titri Fault System: Quaternary-active faults near the leading edge of the Otago reverse fault province, N. Z. J. Geol. Geophys., 44(4), 517-534.

Litchfield, N. J., and K. R. Berryman (2005), Correlation of fluvial terraces within the Hikurangi Margin, New Zealand: Implications for climate and base level controls, Geomorphology, 68(3-4), 291-313.

Long, D. T., S. C. Cox, S. Bannister, M. C. Gerstenberger, and D. Okaya (2003), Upper crustal structure beneath the eastern Southern Alps and the Mackenzie Basin, New Zealand, derived from seismic reflection data, N. Z. J. Geol. Geophys., 46(1), 21-39.

Maizels, J. K. (1989), Differentiation of late Pleistocene terrace outwash deposits using geomorphic criteria-Tekapo Valley, South Island, New Zealand, N. Z. J. Geol. Geophys., 32(2), 225-241.

Martinson, D. G., N. G. Pisias, J. D. Hays, J. Imbrie, T. C. Moore, and N. J. Shackleton (1987), Age dating and the orbital theory of the ice agesDevelopment of a high-resolution 0 to 300,000 - year chronostratigraphy, Quat. Res., 27(1), 1-29.

McClay, K., J. A. Munoz, and J. Garcia-Senz (2004), Extensional salt tectonics in a contractional orogen: A newly identified tectonic event in the Spanish Pyrenees, Geology, 32(9), 737-740.

McSaveney, M. J. (1991), Paleoseismicity of the Irishman Creek Fault by weathering-rind dating, in GSNZ and New Zealand Society of Soil Science: Joint Annual Conference, Palmerston North 1991, November 25-29, edited by R. B. Stewart, A. S. Palmer, and A. Todd, Geol. Soc. N. Z. Misc. Publ., 59A, p. 92.

Medwedeff, D. A., and J. Suppe (1997), Multibend fault-bend folding, J. Struct. Geol., 19, 279-292.

Mildenhall, D. C. (2001), Pollen analysis of Pliocene-Pleistocene Kowa Formation (Kurow Group), Mackenzie Basin, South Canterbury, New Zealand, N. Z. J. Geol. Geophys., 44(1), 97-104.
Molnar, P., E. T. Brown, B. C. Burchfiel, Q. Deng, X. Feng, J. Li, G. M. Raisbeck, J. Shi, Z. Wu, F. Yiou, and H. You (1994), Quaternary climate change and the formation of river terraces across growing anticlines on the north flank of the Tien Shan, China, J. Geol., 102(5), $583-602$.

Nicol, A., and J. K. Campbell (2001), The impact of episodic fault-related folding on late Holocene degradation terraces along Waipara River, New Zealand, N. Z. J. Geol. Geophys., 44(1), 145-156.

Nobes, D., D. Burbank, C. Amos, and K. Davis (2005), 3D imaging of the fore- and backthrusts of the Glen Lyon segment of the Ostler Fault, paper presented at 50th Annual Conference, Geol. Soc. of N. Z., Kaikoura, New Zealand.

Norris, R. J., and A. F. Cooper (2001), Late Quaternary slip rates and slip partitioning on the Alpine Fault, New Zealand, J. Struct. Geol., 23(2-3), $507-520$.

Pan, B., D. Burbank, Y. Wang, G. Wu, J. Li, and Q. Guan (2003), A 900 k.y. record of strath terrace formation during glacial-interglacial transitions in northwest China, Geology, 31(11), 957-960.

Pazzaglia, F. J., and M. T. Brandon (2001), A fluvial record of long-term steady-state uplift and erosion across the Cascadia forearc high, western Washington State, Am. J. Sci., 301(4-5), 385-431.

Pearson, C. F., J. Beavan, D. J. Darby, G. H. Blick, and R. I. Walcott (1995), Strain distribution across the Australian-Pacific plate boundary in the central South Island, New Zealand, from 1992 GPS and earlier terrestrial observations, J. Geophys. Res., 100(B11), 22,071-22,082.

Philip, H., and M. Meghraoui (1983), Structural analysis and interpretation of the surface deformations of the El-Asnam earthquake of October 10, 1980, Tectonics, 2(1), 17-49.

Pinter, N., B. Johns, B. Little, and W. D. Vestal (2001), Fault-related folding in California's northern Channel Islands documented by rapid static GPS positioning, GSA Today, 11(5), 4-9.

Poblet, J., and K. McClay (1996), Geometry and kinematics of single-layer detachment folds, AAPG Bull., 80(7), 1085-1109.

Prescott, J. R., and J. T. Hutton (1995), Environmental dose-rates and radioactive disequilibrium from some Australian luminescence dating sites, Quat. Sci. Rev., 14(4), 439-448.

Putkonen, J., and T. Swanson (2003), Accuracy of cosmogenic ages for moraines, Ouat. Res., 59(2), 255-261.

Read, S. A. L. (1984), The Ostler Fault Zone, in Guidebook to the South Island Scientific Excursions International Symposium on Recent Crustal Movements of the Pacific Region, edited by P. R. Wood, pp. 121-134, R. Soc. of N. Z., Wellington.

Read, S. A. L., and G. H. Blick (1991), Late Quaternary deformation and geodetic monitoring in the area of "the knot" on the Ostler fault zone, South Island, New Zealand, N. Z. Geol. Surv. Rec., 43, 85-91.

Rockwell, T. K., E. A. Keller, M. N. Clark, and D. L. Johnson (1984), Chronology and rates of faulting of Ventura river terraces, California, Geol. Soc. Am. Bull., 95(12), 1466-1474.

Rockwell, T. K., E. A. Keller, and G. R. Dembroff (1988), Quaternary rate of folding of the Ventura Avenue Anticline, western Transverse Ranges, southern California, Geol. Soc. Am. Bull., 100(6), 850-858.

Schaefer, J. M., U. Ninnemann, G. H. Denton, C. Schluechter, S. Ivy-Ochs, R. Wieler, P. W. Kubik, B. G. Anderson, and P. Schlosser (2001), Structure of the Last Glacial Maximum in New Zealand-Terrestrial and marine evidence from southern mid-latitudes, Eos Trans. AGU, 82(47), Fall Meet. Suppl., Abstract PP42B-0499.

Schaefer, J. M., G. H. Denton, D. J. A. Barrell, S. Ivy-Ochs, P. W. Kubik, B. G. Andersen, F. M. Phillips, T. V. Lowell, and C. Schluchter (2006), Near-synchronous interhemispheric termination of the Last Glacial Maximum in mid-latitudes, Science, 312(5779), 1510-1513.

Scharer, K. M., D. W. Burbank, J. Chen, and R. J. Weldon (2006), Kinematic models of fluvial terraces over active detachment folds: Constraints on the growth mechanism of the Kashi-Atushi fold system, Chinese Tian Shan, Geol. Soc. Am. Bull, 118(7), 1006-1021.

Seeber, L., and C. C. Sorlien (2000), Listric thrusts in the western Transverse Ranges, California, Geol. Soc. Am. Bull., 112(7), 1067-1079.

Stein, R. S., and G. C. P. King (1984), Seismic potential revealed by surface folding-1983 Coalinga, California, earthquake, Science, 224(4651) $869-872$.

Suggate, R. P. (1990), Late Pliocene and Quaternary glaciations of NewZealand, Quat. Sci. Rev., 9(2-3), 175-197.

Suppe, J. (1983), Geometry and kinematics of fault-bend folding, Am. J. Sci., 283(7), 684-721

Suppe, J., and D. A. Medwedeff (1990), Geometry and kinematics of faultpropagation folding, Eclogae Geol. Helv., 83(3), 409-454.

Suppe, J., G. T. Chou, and S. C. Hook (1992), Rates of folding and faulting determined from growth strata, in Thrust Tectonics, edited by K. R. McClay, pp. 105-121, CRC Press, Boca Raton, Fla.

Suppe, J., C. D. Connors, and Y. Zhang (2004), Shear fault-bend folding, $A A P G$ Mem, 82, 303-323. 
Thompson, S. C., R. J. Weldon, C. M. Rubin, K. Abdrakhmatov, P. Molnar, and G. W. Berger (2002), Late Quaternary slip rates across the central Tien Shan, Kyrgyzstan, central Asia, J. Geophys. Res., 107(B9), 2203, doi:10.1029/2001JB000596.

Tippett, J. M., and N. Hovius (2000), Geodynamic processes in the Southern Alps, New Zealand, in Geomorphology and Global Tectonics, edited by M. A. Summerfield, John Wiley, Hoboken, N. J.

van Dissen, R. J., A. G. Hull, and S. A. L. Read (1994), Timing of some large Holocene earthquakes on the Ostler Fault, New Zealand, in Proceedings of the CRCM 1993, pp. 381-386, Geod. Soc. of Jpn., Kobe, Japan.

Wernicke, B., and B. C. Burchfiel (1982), Modes of extensional tectonics, J. Struct. Geol., 4(2), 105-115.

Yamada, Y., and K. McClay (2003), Application of geometric models to inverted listric fault systems in sandbox experiments. Paper 1: 2D hanging wall deformation and section restoration, J. Struct. Geol., 25(9), $1551-1560$
Yilmaz, O. (2001), Seismic Data Analysis: Processing, Inversion, and Interpretation of Seismic Data, 2027 pp., Soc. of Explor. Geophys. Tulsa, Okla.

C. B. Amos and D. W. Burbank, Department of Earth Science, University of California, Santa Barbara, CA 93106, USA. (cbamos@crustal.ucsb.edu; burbank@crustal.ucsb.edu)

D. C. Nobes, Department of Geological Sciences, University of Canterbury, Private Bag 4800, Christchurch, New Zealand. (david.nobes@ canterbury.ac.nz)

S. A. L. Read, Institute of Geological and Nuclear Sciences Ltd., P.O. Box 30-368, Lower Hutt, 6009, New Zealand. (s.read@gns.cri.nz) 